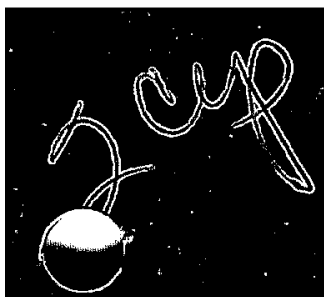

REGENED BY TIC NOV 21972

\title{
EXAMINATION OF IRRADIATED URANIUM NITRIDE FUEL CLAD WITH TUNGSTEN-RHENIUM OR T-111 ALLOY
}

D. R. Cuneo

E. L. Long, Jr.

A. Jostsons

T. N. Washburn

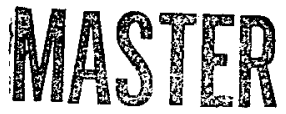

DISTRIBUTION OF THIS DOCUMENT IS UNLIAITED

\section{OAK RIDGE NATIONAL LABORATORY}

OPERATED BY UNION CARBIDE CORPORATION - FOR THE U:S: ATOMIC ENERGY COMMISSION 


\section{DISCLAIMER}

This report was prepared as an account of work sponsored by an agency of the United States Government. Neither the United States Government nor any agency Thereof, nor any of their employees, makes any warranty, express or implied, or assumes any legal liability or responsibility for the accuracy, completeness, or usefulness of any information, apparatus, product, or process disclosed, or represents that its use would not infringe privately owned rights. Reference herein to any specific commercial product, process, or service by trade name, trademark, manufacturer, or otherwise does not necessarily constitute or imply its endorsement, recommendation, or favoring by the United States Government or any agency thereof. The views and opinions of authors expressed herein do not necessarily state or reflect those of the United States Government or any agency thereof. 


\section{DISCLAIMER}

Portions of this document may be illegible in electronic image products. Images are produced from the best available original document. 
This report was prepared as an account of work sponsored by the United States Government. Neither the United States nor the United States Atomic Energy Commission, nor any of their employees, nor any of their contractors, subcontractors, or their employees, makes any warranty, express or implied, or assumes any legal liability or responsibility for the accuracy, completeness or usefulness of any information, apparatus, product or process disclosed, or represents that its use would not infringe privately owned rights. 
Contract No. W-7405-eng-26

METALS AND CERAMICS DIVISION

\section{EXAMINATION OF IRRADIATED URANIUM NITRIDE FUEL} CLAD WITH TUNGGSTEN-RHENIUM OR T-111 ALLOY

D. R. Cuneo, E. L. Long, Jr., A. Jostsons, and T. N. Washburn

$$
\text { NOTICE }
$$

This report was prepared as an account of work sponsored by the United States Government. Neither the United States nor the United States Atomic Energy Commission, nor any of their employes, nor any of

Commission, nor any of their employees, nor any of

their contractors, subcontractors, or their employees,

makes any warranty, express or implied, or assumes any

legal liability or responsibility for the accuracy, com-

pleteness or usefulness of any information, apparatus,

product or process disclosed, of represents that its use

would not infringe privately owned rights.

OCTOBER 1972

\footnotetext{
OAK RIDGE NATIONAL IABORATORY

Oak Ridge, Tennessee 37830

operated by

UNION CARBIDE CORPORATION

for the
}

U.S. ATOMIC ENERGY COMMISSION 
Abstract . . . . . . . . . . . . . . . . . . 1

Introduction . . . . . . . . . . . . . . . . . . 2

Experiment Description . . . . . . . . . . . . . . 3

Irradiation History . . . . . . . . . . . . . . . . . . . 4

Capsule Disassembly . . . . . . . . . . . . . . . . . 4

Nondestructive Examination of Fuel Pins . . . . . . . . . . . . 5

Visual Examination . . . . . . . . . . . . . . 5

Dye-Penetrant Inspection . . . . . . . . . . . . . 8

Gamma Scanning . . . . . . . . . . . . . . . . . 9

Dimensional Inspection . . . . . . . . . . . . . . 9 9

Neutron Radiography .................. 13

Fission Gas Analysis . . . . . . . . . . . . . . . . 14

Sectioning and Metallography . . . . . . . . . . . . . . 16

Top Fuel Pin .. . . . . . . . . . . . . . . 16

Middle Fuel Pin . . . . . . . . . . . . . . . 21

Bottom Fuel Pin ................. . 27

Fuel Burnup . . . . . . . . . . . . . . . . . . . 28

Fuel Swelling . . . . . . . . . . . . . . . . . 29

Examination of T-lll Cladding . . . . . . . . . . . . . 32

Nitrogen in Cladding . . . . . . . . . . . . . 32

Microhardness . . . . . . . . . . . . . . 33

Grain Size .. . . . . . . . . . . . . . 34

Electron Microprobe . . . . . . . . . . . . . 34

Scanning Electron Microscopy . . . . . . . . . . . 35

Discussion of Cavity Formation and Intergranular Fracture . . 36

Conclusions . . . . . . . . . . . . . . . . . 40

Performance of UN Fuel . . . . . . . . . . . . . 40

Top Fuel Pin . . . . . . . . . . . . . . . . 41

Middle Fuel Pin... . . . . . . . . . . . . . . 41

Bottom Fuel Pin... . . . . . . . . . . . . . 42

Acknowledgments . . . . . . . . . . . . . . . . 42

Appendix . . . . . . . . . . . . . . . . . . 43 
EXAMINATION OF IRRADIATED URANIUM NITRIDE FUEL· CLAD WITH TUNGSTEN-RHENIUM OR T-11.1 ALLOY

D. R. Cuneo, E. L. Long, Jr., A. Jostsons, ${ }^{l}$ and T. N. Washburn

\section{ABSTRACT}

Three fuel pins containing UN pellets were irradiated in the thermal neutron flux of the ORR for $5800 \mathrm{hr}$ to a peak burnup of 1.75 at. \%. The pin with $\mathrm{W}-25 \%$ Re cladding performed satisfactorily with the cladding outer surface at $1300^{\circ} \mathrm{C}$. The two pins with $\mathrm{T}-11 \mathrm{l}$ ( $\mathrm{Ta}-8 \% \mathrm{~W}-2 \% \mathrm{Hf}$ ) cladding, which had an inner liner of chemically vapor deposited tungsten, operated with the cladding outer surface at $1400^{\circ} \mathrm{C}$. The $\mathrm{T}-111$ on one of the pins failed during the test by intergranular fracture. The grain size in the failed region was 6 times that in the gas plenum region, indicating that failure was caused by a localized hot spot. However, numerous cracks and cavities were found in other regions of the T-lll cladding of both the failed and unfailed pins, and we conclude that the cladding on both of these pins would have ultimately failed without the hot spot. Hafnium-rich areas, with concentrations 30 to 40 times that in the homogeneous alloy, were detected by electron microprobe examination at the cracks and cavities in both the T-IIl and the tungsten liner. We were not able to determine the mechanism of the test-induced concentration of hafnium.

The UN fuel performed satisfactorily in all three pins. The fission-gas release was only $0.1 \%$ at $1380^{\circ} \mathrm{C}$ (top pin) and $7.1 \%$ at $1500^{\circ} \mathrm{C}$ (bottom pin). Swelling of the fuel was adequately restrained by the cladding and was limited to closing of the asfabricated 0.005-in. gap between fuel and cladding. No gross chemical reaction occurred between the fuel and cladding. Although they interacted to a depth of about $20^{\circ} \mathrm{\mu m}$, electron microprobe analysis of the cladding revealed no uranium penetration beyond that depth. Nitrogen released from the UN may have interacted with the T-lll and led to the degradation of its mechanical properties.

IOn attachment from Australian Atomic Energy Commission Research Establishment, Lucas Heights, N.S.W. 


\section{INTRODUCTION}

Uranium mononitride is attractive as a fuel for nuclear reactors in space applications because of its high fissile density, high melting point, good thermal conductivity, and apparent irradiation stability. The basic objective of the ORNL Program ${ }^{2}$ is to investigate the performance capability of UN fuel operating at linear heat ratings of 5 to $10 \mathrm{~kW} / \mathrm{ft}$ and fuel center-line temperatures in the range 1000 to $1500^{\circ} \mathrm{C}$. These irradiation parameters require the use of refractory metal cladding operating at outside surface temperatures in the range 900 to $1400^{\circ} \mathrm{C}$. The main emphasis of these tests is to determine fuel swelling, fission gas release, and compatibility of the fuel with cladding materials.

The specific objective of this experiment (Capsule UN-3) was to evaluate the performance capability of UN fuel pins at the upper limits of interest in this program; namely, outside cladding surface temperature of $1400^{\circ} \mathrm{C}$, a fuel center-line temperature of $1500^{\circ} \mathrm{C}$, and a linear heat rating of $9 \mathrm{~kW} / \mathrm{ft}$. This capsule was irradiated in the poolside facilities of the Oak Ridge Research Reactor (ORR). for $5800 \mathrm{hr}$ of an intended 10,000-hr test. The test was terminated when one of the fuel pins failed, as indicated by radioactivity in the capsule sweep gas. Some of the results of postirradiation examinations of this capsule (UN-3) have been described in progress reports ${ }^{3-6}$ and elsewhere. ${ }^{7}, 8$

${ }^{2}$ The current program includes work sponsored by the Atomic Energy Commission (AEC) and work sponsored by the National Aeronautics and Space Administration (NASA) under Interagency Agreement 40-184-69, NASA Order C-54536-B. Specifically, capsules UN-1, UN-2, UN-3, and UN-6 are funded by $A E C$, and capsules UN -4 and UN -5 are funded by NASA.

${ }^{3}$ D. R. Cuneo, Fuels and Materials Development Program Quart. Progr. Rept. Dec. 31, 1969, ORNL-4520, pp. 195-201.

${ }^{4}$ D. R. Cuneo and E. L. Long, Jr., Fuels and Materials Development Program Quart. Progr. Rept. March 31, 1970, ORNL-4560, pp. 165-172.

${ }^{5}$ D. R. Cuneo and E. L. Long, Jr., Fuels and Materials Development Program Quart. Progr. Rept. June 30, 1970, ORNL-4600, pp. 177-180.

${ }^{6} \mathrm{E} . \mathrm{L}$. Long, Jr., and D. R. Cuneo, Fuels and Materials Development Program Quart. Progr. Rept. Sept. 30, 1970, ORNL-4630, pp. 180-185. 
EXPERIMENT DESCRIPTION

Capsule UN-3 contained three collinear fuel pins as shown in Fig. 1. Each pin was $4.5 \mathrm{in}$. long and contained ten 0.3 -in.-OD UN pellets. The fuel column length was $3 \mathrm{in}$. in the top fuel pin and $2.6 \mathrm{in}$. in both the middle and bottom fuel pins. The fuel pellets in the top pin were hollow (0.105-in.-diam hole) to accommodate a thermowell, whereas the pellets in the lower two pins were solid. The two lower pins had 12.9\%-enriched ${ }^{235} \mathrm{U}$, but the fuel in the top pin had $20 \%$-enriched $235 \mathrm{U}$, to partially compensate for the lower neutron flux at the top pin position. A 0.005-in. helium-filled diametral gap existed between the fuel pellets and the cladding when fabricated. A 0.003-in.-thick layer of tungsten was vapordeposited on the inner surface of the r-lll cladding to separate the UN fuel from the $\mathrm{T}-111$, since these materials are considered not to be compatible at the test conditions.

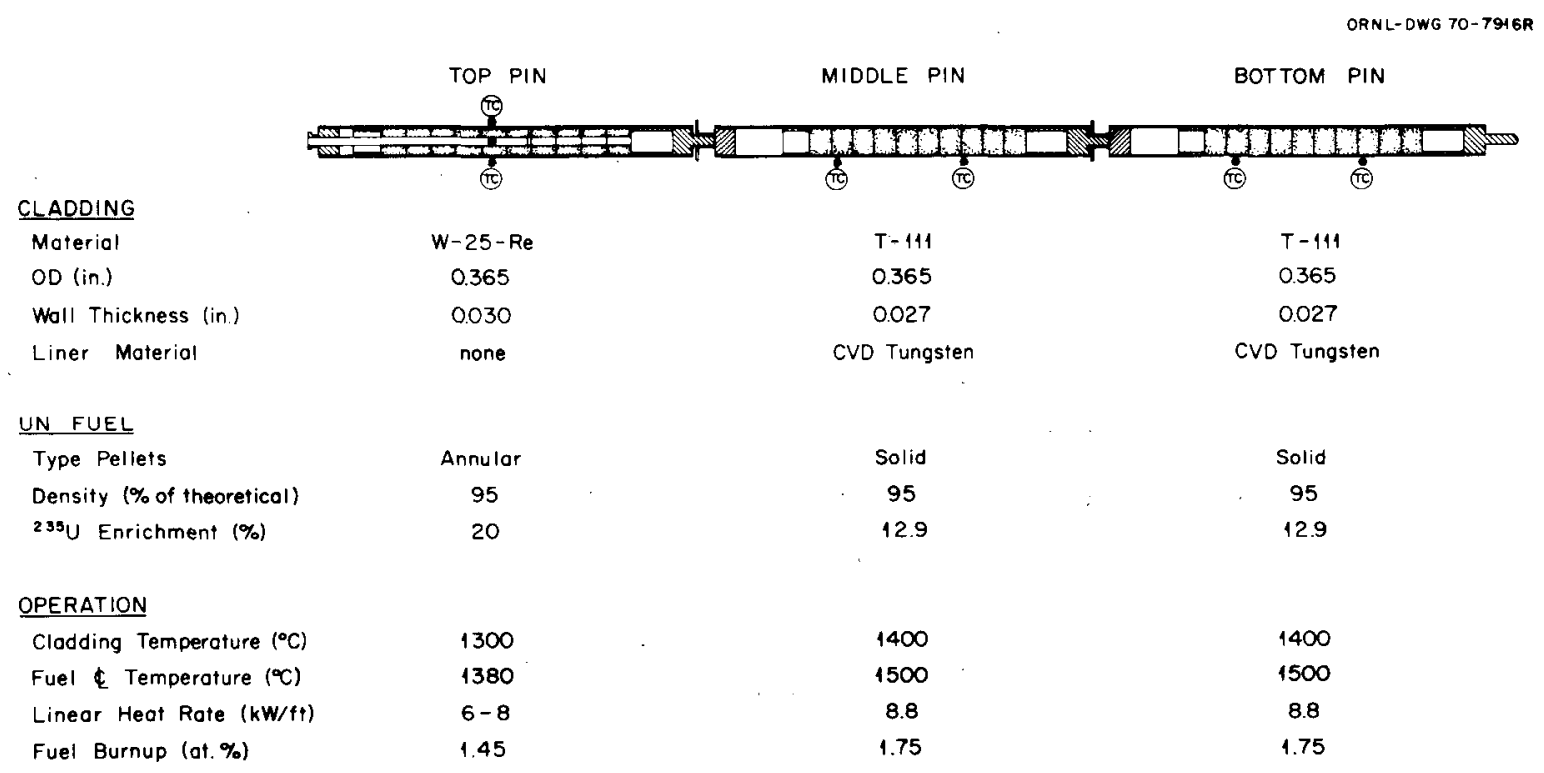

Fig. 1. Design of Fuel Pins of Capsule UN-3.

7T. N. Washburn, D. R. Cuneo, and E. L. Long, Jr., "Irradiation Performance of Uranium Nitride at $1500^{\circ} \mathrm{C}$ " Amer. Ceram. Soc. Bull. 50, 427 (1971).

${ }^{8}$ T. N. Washburn, K. R. Thoms, S. C. Weaver, D. R. Cuneo, and E. L. Long, Jr., "Examination of UN-Fueled Pins Irradiated at $1400^{\circ} \mathrm{C}$ Cladding Temperature," Trans. Amer. Nucl. Soc. 13(1), 102 (1970). 
The fuel pins were surrounded by static NaK coolant within an $\mathrm{Nb}-1 \% \mathrm{Zr}$ sleeve. Type 304 stainless steel was used for the primary containment vessel of the capsule. Each of the fuel pins had two tantalum-sheathed thermocouples strapped to the outer surface of the cladding, and the top pin had a thermocouple for measuring fuel center-line temperature; relative locations of these thermocouples are shown in Fig. 1. A more complete description of the irradiation capsule used in the ORNL program on irradiation testing of UN has been reported previous 1 y. ${ }^{9}$

\section{IRRADIATION HISTORY}

Capsule UN-3 was irradiated in the ORR poolside position 5 at an estimated time-averaged thermal flux in the middle and bottom fuel pins of $1.4 \times 10^{13}$ neutrons $\mathrm{cm}^{-2} \mathrm{sec}^{-1}$, while that in the top pin was $8.7 \times 10^{12}$ neutrons $\mathrm{cm}^{-2} \mathrm{sec}^{-1}$. The fast flux $(>1 \mathrm{MeV}$ ) was about $5 \times 10^{12}$ neutrons $\mathrm{cm}^{-2} \mathrm{sec}^{-1}$. At the termination of the test the fast fluence of the bottom and midale pins was about $1 \times 10^{20}$ neutrons $/ \mathrm{cm}^{2}$, and that of the top pin was $0.6 \times 10^{20}$ neutrons $/ \mathrm{cm}^{2}$. The experiment was designed for a temperature of $1400^{\circ} \mathrm{C}$ on the cladding outside surface. Because of the flux distribution in the reactor test position, the cladding of the top fuel pin operated at a lower temperature of $1300^{\circ} \mathrm{C}$, even though the ${ }^{235} \mathrm{U}$ enrichment in this pin was higher to minimize the difference in operating temperature. With a temperature of $1300^{\circ} \mathrm{C}$ at the outside surface of the cladding, the fuel center-line temperature of the top pin was $1380^{\circ} \mathrm{C}$ at the beginning of the test and $1330^{\circ} \mathrm{C}$ at the end of the test.

\section{CAPSULE DISASSEMBLY}

Two significant observations were made during disassembly of the capsule. The tantalum thermocouple strap had self-welded to the cladding

\footnotetext{
${ }^{9}$ V. A. DeCarlo, F. R. McQuilkin, R. L. Senn, K. R. Thoms, and S. C. Weaver, Design of a Capsule for Irradiation Testing of Uranium Nitride Fuel, ORNL-TM-2363 (February 1969).
} 
of the bottom fuel pin, and one thermocouple sheath, which terminated at midlength of the top fuel pin, had self-welded to the fuel pin for a distance of about $1.5 \mathrm{in.}$, as shown in Fig. 2. This couple had been pulled loose before removal of the fuel pins from the niobium-zirconium sleeve. When removed from the capsule 30 days after irradiation, the NaK coolant gave a reading of about $10 \mathrm{R} / \mathrm{hr}$, thus confirming earlier indications of a failed fuel pin within the capsule.

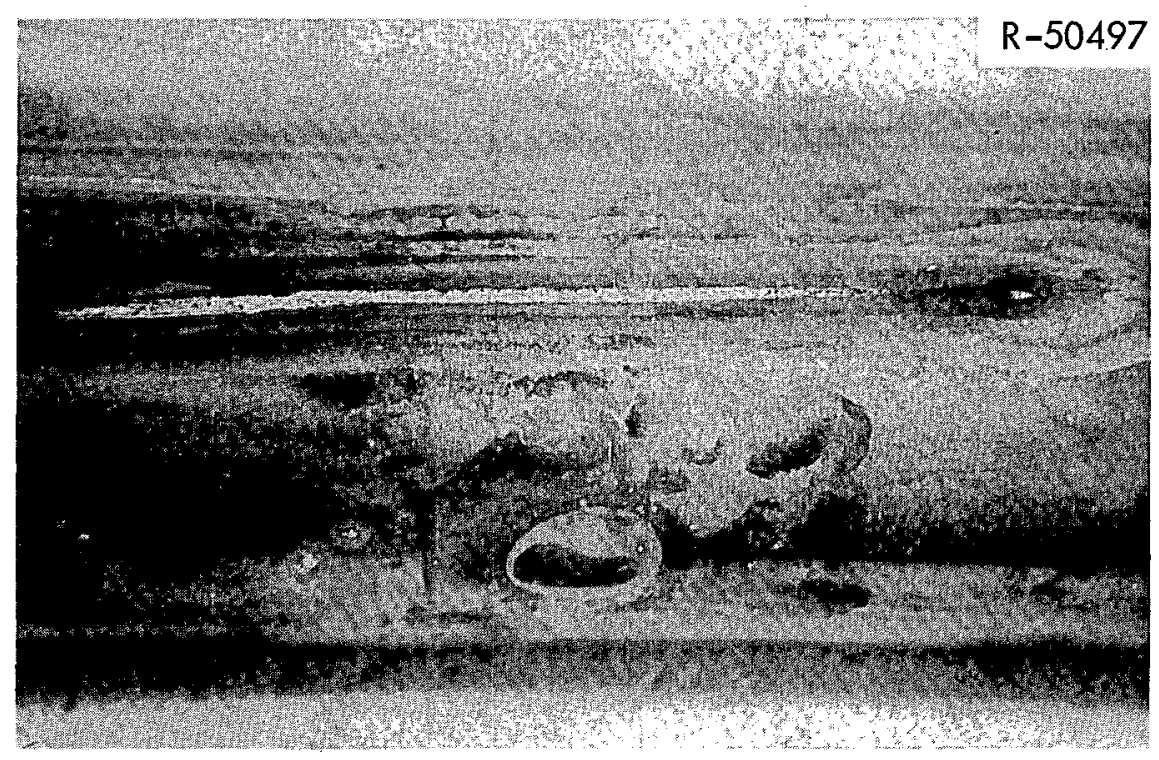

Fig. 2. Location of Self-Welding of Thermocouple to Top Fuel Pin Cladding, Capsule UN-3. $5.5 \times$.

\section{NONDESTRUCTIVE EXAMINATION OF FUEL PINS}

\section{Visual Examination}

Visual examination of the fuel pins revealed several short cracks in the cladding of the middle pin. Generally, these cracks were parallel to the long axis of the pin. Figure 3 shows the three fuel pins with an enlarged view of the middle pin. Figure 4 gives dimensional details regarding crack locations. Locations of the cracks are related to the thermocouple straps in Fig. 5. 


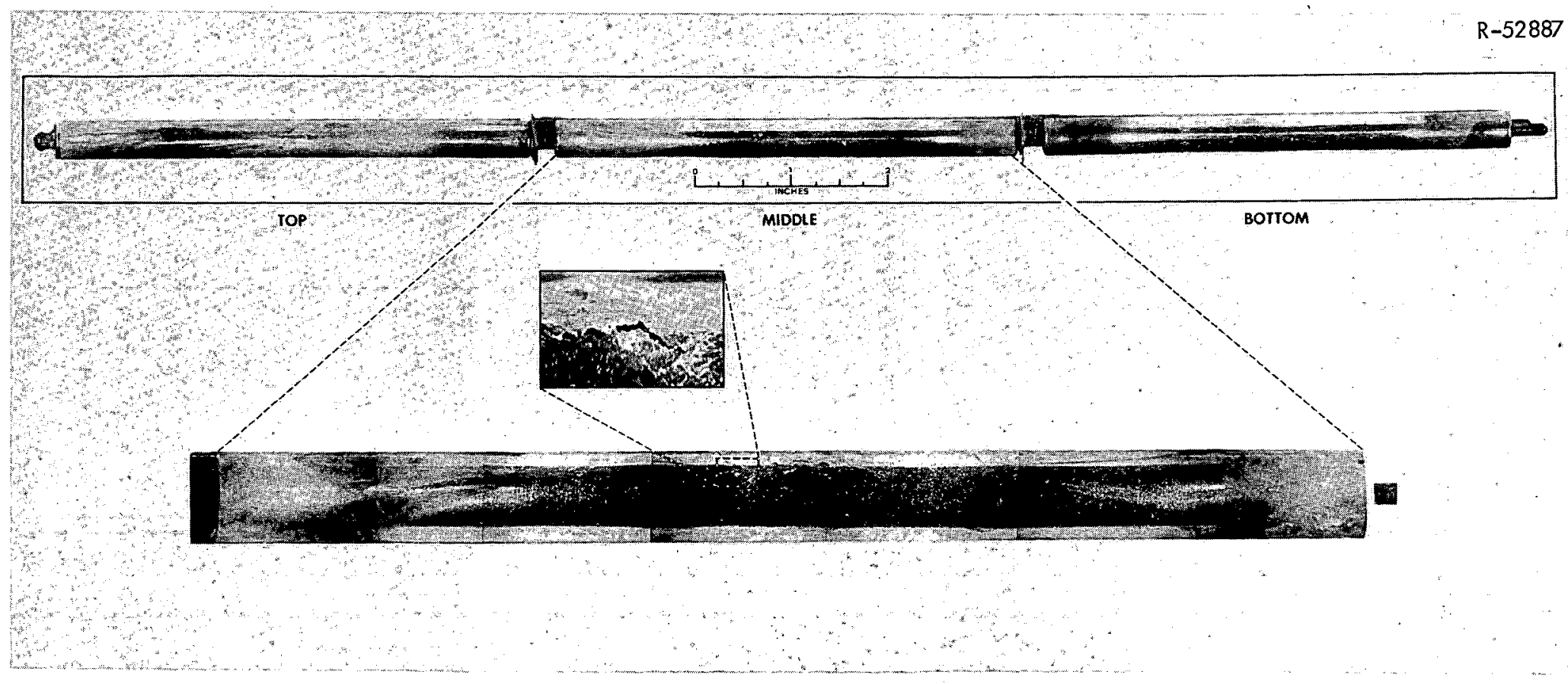

Fig. 3. Overall View of the Three Fuel Pins in'Capsule UN-3, with an Enlarged View of the Middle Pin and its Major Crack. 
ORNL-DWG 70-519
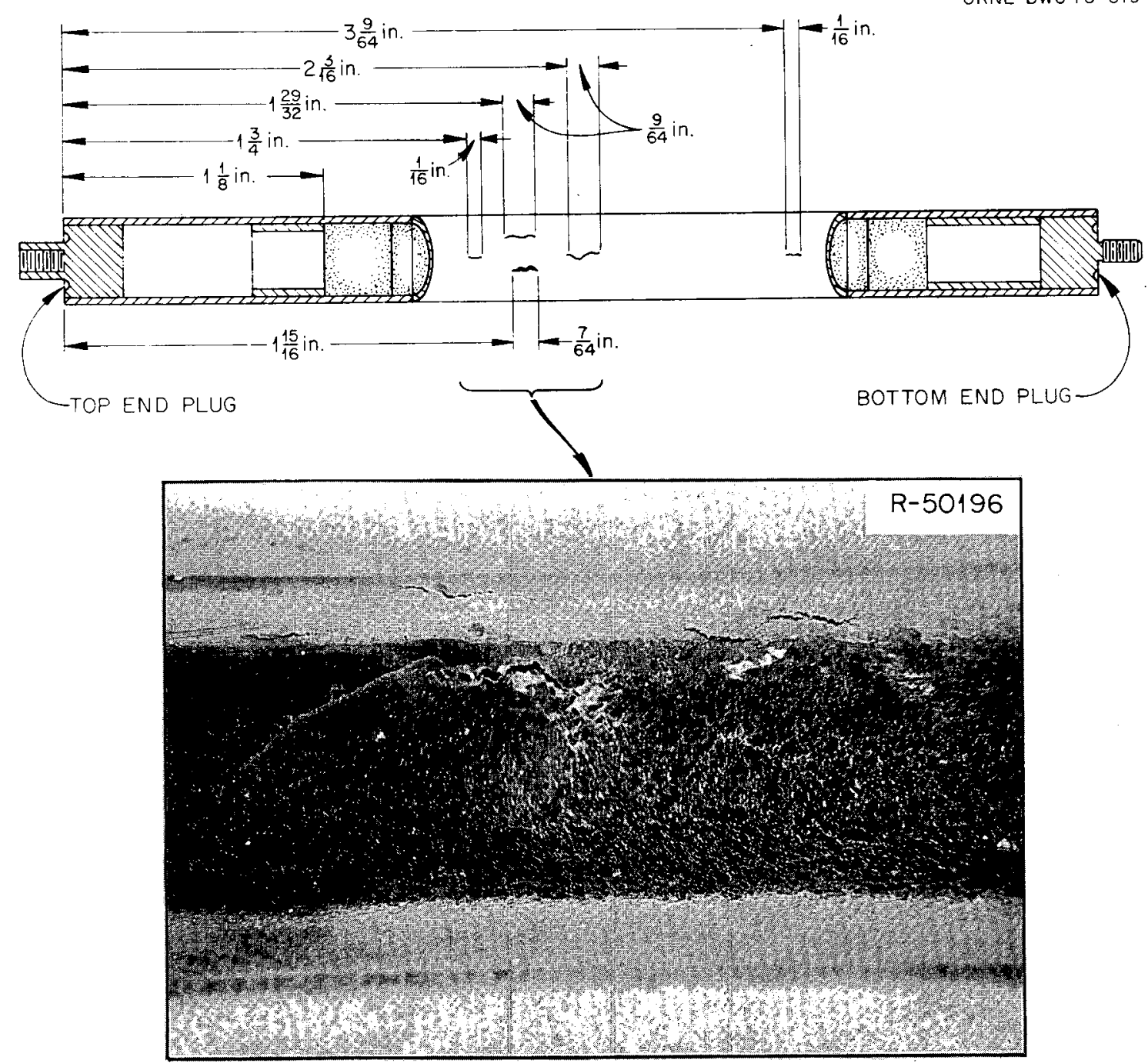

Fig. 4. Location of Cracks in Cladding of Middle Fuel Pin of Capsule UN-3. 


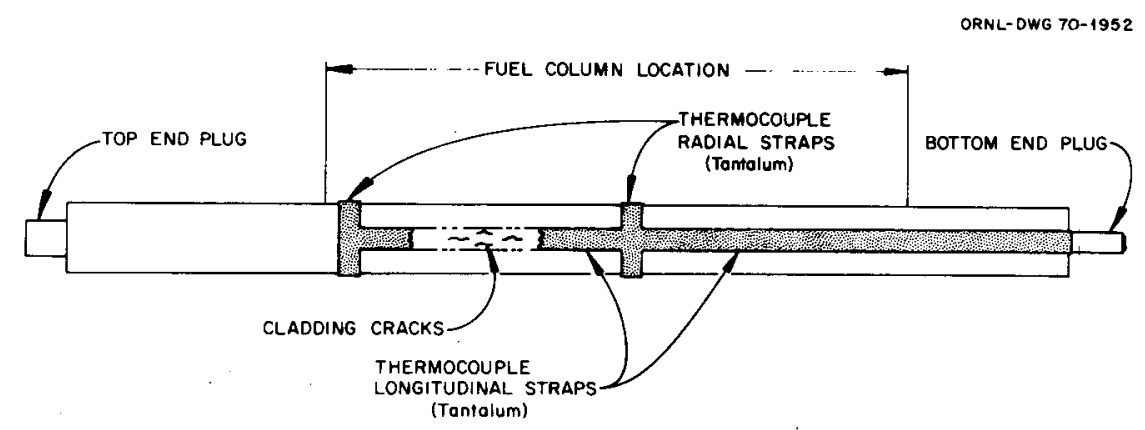

Fig. 5. Location of Cladding Cracks Relative to Thermocouple Straps on Middle Fuel Pin of Capsule UN-3.

Both pins with T-1ll cladding (middle and bottom) were shiny over the fueled regions. In this region of the middle pin, grains in the cladding were distinctly outlined; this indicates thermal etching by the NaK. The $\mathrm{W}-25 \%$ Re cladding on the top pin did not show this effect.

Dyje-Penetrant Inspection

Dye-penetrant inspections determined that the cladding of the top and bottom fuel pins had remained sound during the irradiation test. Results of the dye-penetrant tests for the middle fuel pin are seen in Fig. 6. The white areas on the pin are due to dye penetrant in cracks and were photographed by a 20-min exposure to ultraviolet light.

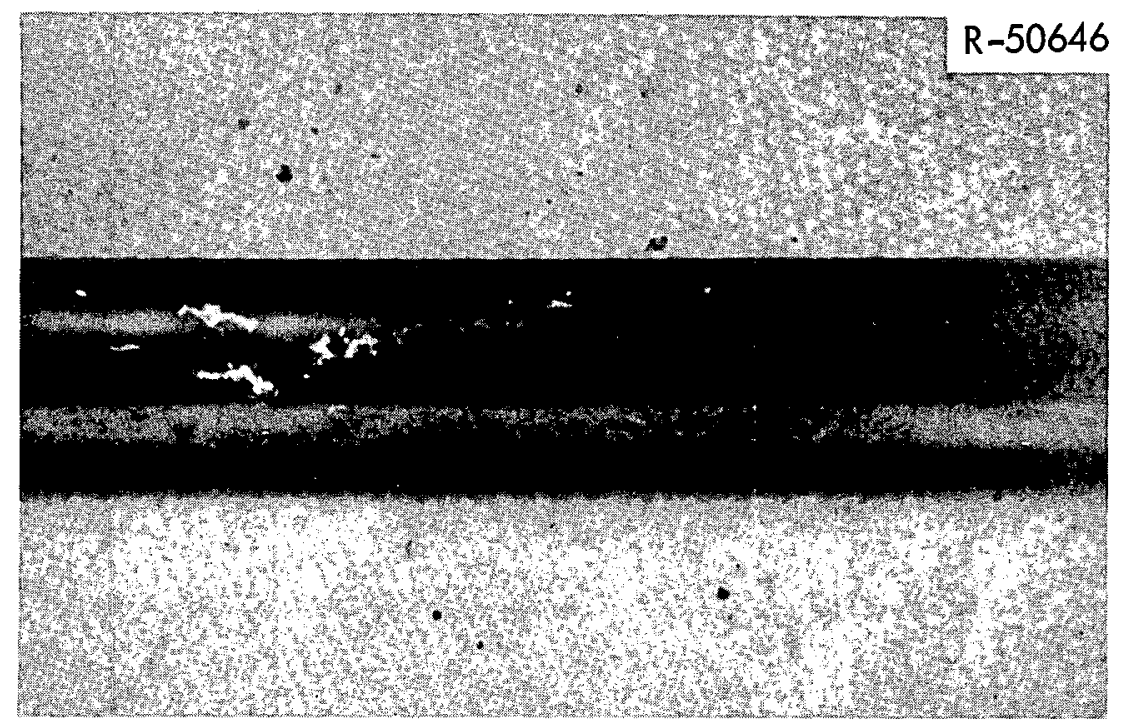

Fig. 6. Cracks in Cladding of Middle Fuel Pin, Capsule UN-3, As Shown by Dye Penetrant. 2.1X. 
Gamma Scanning

Typical gamma scans along the fuel pins, Fig. 7, showed no unusual characteristics. The top fuel pin scan showed no activity other than from the fueled portion because the tungsten-rhenium cladding and end plugs do not have activation products with sufficient half-lives to be found beyond a short time after removal from the reactor. Activated components of the T-11l cladding and end plugs were clearly defined for the middle and bottom pins. These scans were taken in the energy range 0.75 to $0.85 \mathrm{MeV}$, which is sensitive particularly to ${ }^{95} \mathrm{Zr}-\mathrm{No}$. Multienergy scans were taken in both fueled and unfueled regions of the fuel pins and yielded normal findings.
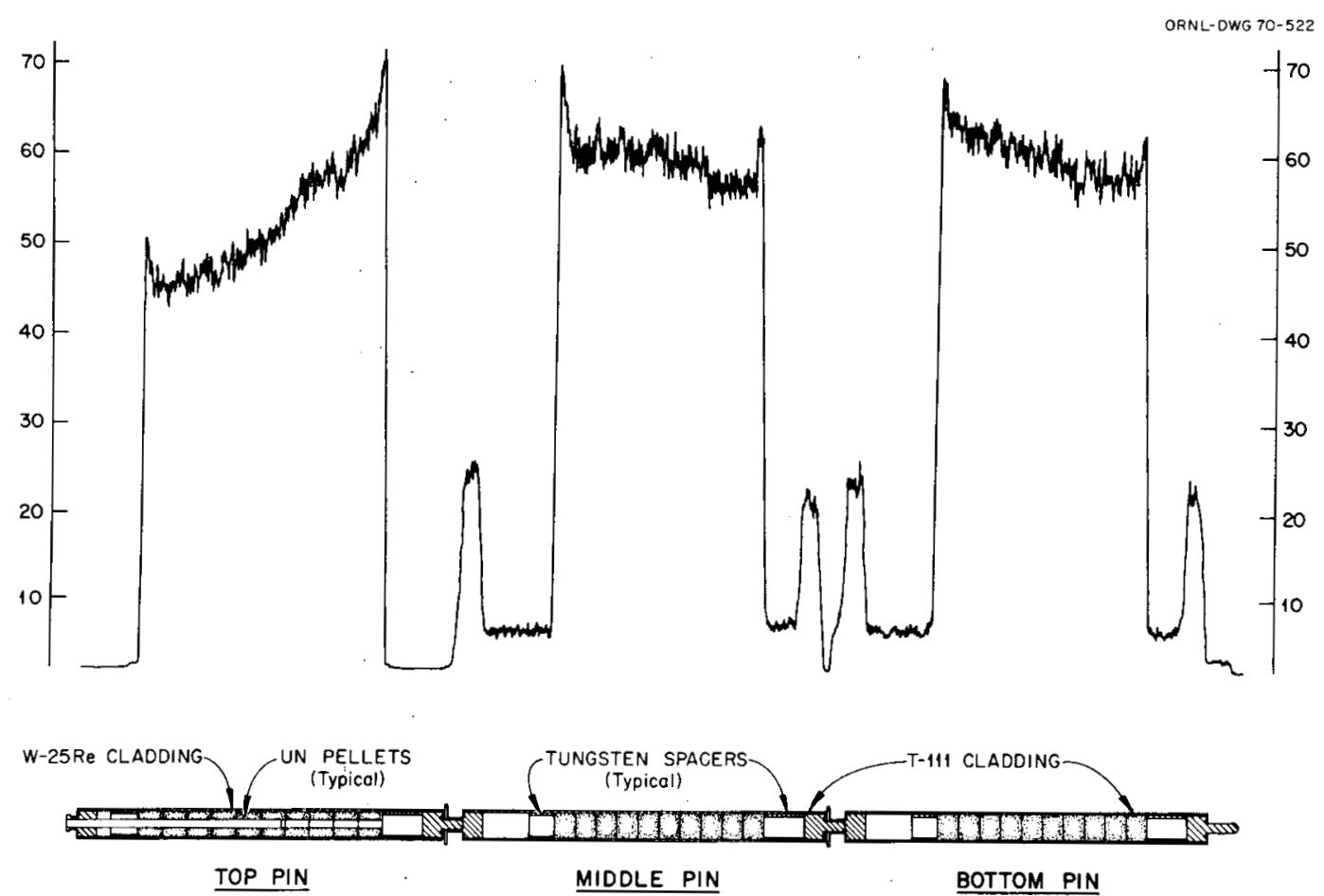

Fig. 7. Gamma Scan Activity of Fuel Pins in Capsule UN-3 (0.75 to 0. $85 \mathrm{MeV})$.

Dimensional Inspection

Measurements of the pin diameters with an opposed-dial-gage profilometer are shown in Figs. 8 and 9 and in Table 1. The agreement between 
post- and preirradiation measurements in the regions of the end plugs indicates the absence of significant discrepancies between pre- and posttest measurement techniques. Each of the fuel pins had some reduction in diameter during irradiation. This was most pronounced in the top fuel pin, which had a maximum decrease in diameter of 0.003 in. just below

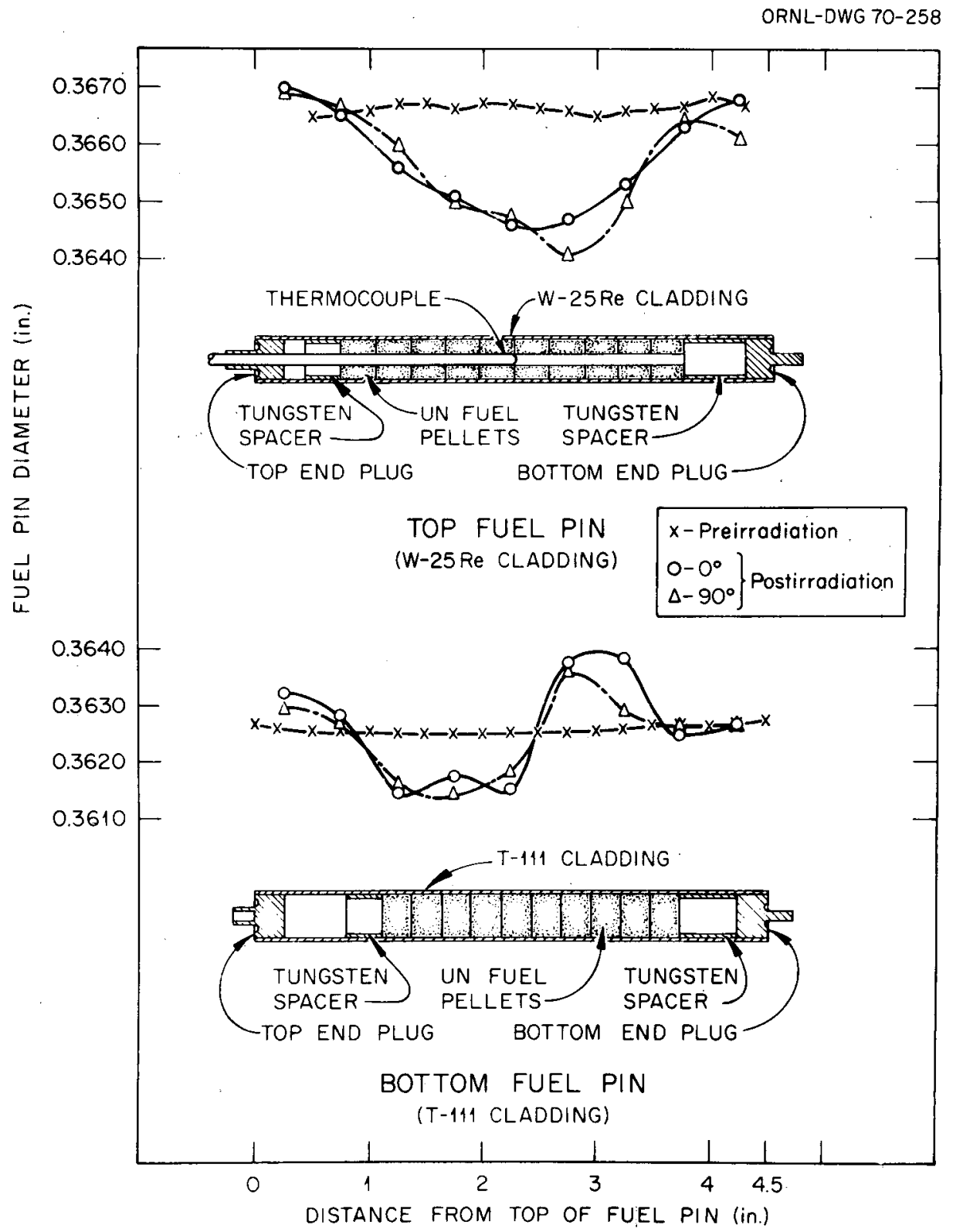

Fig. 8. Comparison of Diameters of Top and Bottom Fuel Pins of Capsule UN-3 Before and After Irradiation. 


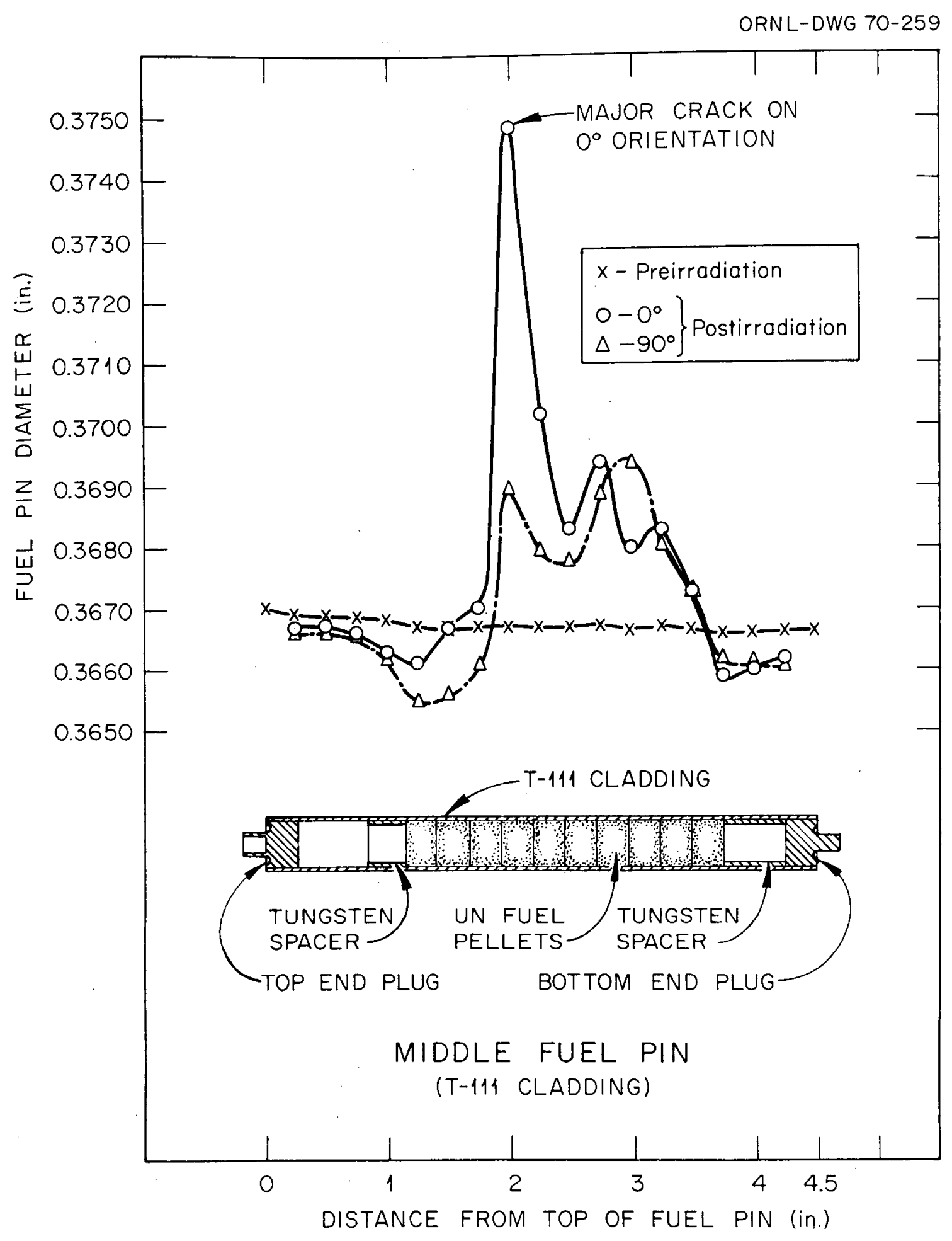

Fig. 9. Comparison of Diameters of Middle Fuel Pin of Capsule UN-3 Before and After Irradiation. 
Table 1. Diameter Measurements Taken from the Three Fuel Pins in Capsule UN-3

\begin{tabular}{|c|c|c|c|}
\hline \multirow{2}{*}{ Fuel Pin } & \multirow{2}{*}{$\begin{array}{l}\text { Location Measured } \\
\text { (in. from top of pin) }\end{array}$} & \multicolumn{2}{|c|}{ Diameter, in. } \\
\hline & & $0^{\circ}$ & $90^{\circ}$ \\
\hline \multirow[t]{9}{*}{ Top } & 0.25 & 0.3670 & 0.3669 \\
\hline & 0.75 & 0.3665 & 0.3667 \\
\hline & 1.25 & 0.3656 & 0.3660 \\
\hline & 1.75 & 0.3651 & 0.3650 \\
\hline & 2.25 & 0.3646 & 0.3648 \\
\hline & 2.75 & 0.3647 & 0.3641 \\
\hline & 3.25 & 0.3653 & 0.3650 \\
\hline & 3.75 & 0.3663 & 0.3664 \\
\hline & 4.25 & 0.3668 & 0.3661 \\
\hline \multirow[t]{17}{*}{ Middle } & 0.25 & 0.3667 & 0.3666 \\
\hline & 0.50 & 0.3667 & 0.3666 \\
\hline & 0.75 & 0.3666 & 0.3666 \\
\hline & 1.00 & 0.3663 & 0.3662 \\
\hline & 1.25 & 0.3661 & 0.3655 \\
\hline & 1.50 & 0.3667 & 0.3656 \\
\hline & 1.75 & 0.3670 & 0.3661 \\
\hline & 2.00 & $0.3749^{\mathrm{a}}$ & 0.3690 \\
\hline & 2.25 & 0.3702 & 0.3680 \\
\hline & 2.50 & 0.3683 & 0.3678 \\
\hline & 2.75 & 0.3694 & 0.3689 \\
\hline & 3.00 & 0.3680 & 0.3694 \\
\hline & 3.25 & 0.3683 & 0.3681 \\
\hline & 3.50 & 0.3673 & 0.3673 \\
\hline & 3.75 & 0.3659 & 0.3662 \\
\hline & 4.00 & 0.3660 & 0.366 .1 \\
\hline & 4.25 & 0.3662 & 0.3661 \\
\hline \multirow[t]{9}{*}{ Bottom } & 0.25 & 0.3632 & 0.3629 \\
\hline & 0.75 & 0.3628 & 0.3627 \\
\hline & 1.25 & 0.3614 & 0.3616 \\
\hline & 1.75 & 0.3617 & 0.3614 \\
\hline & 2.25 & 0.3615 & 0.3618 \\
\hline & 2.75 & 0.3637 & 0.3636 \\
\hline & 3.25 & 0.3638 & 0.3629 \\
\hline & 3.75 & 0.3625 & 0.3626 \\
\hline & 4.25 & 0.3626 & 0.3626 \\
\hline
\end{tabular}


the end of the central thermocouple well. The bottom fuel pin had a diameter decrease of about 0.001 in. near the top of the fuel column but an increase of about 0.0015 in. near the bottom of the fuel column. Diameter measurements at 0 and $90^{\circ}$ orientations indicated an ovality of less than 0.001 in. in the irradiated pins. In measuring the diameters on the midale (failed) pin, a $0^{\circ}$ orientation was selected to obtain the maximum diameter at the largest crack. Therefore, the differences between readings at 0 and $90^{\circ}$ orientations do not necessarily indicate ovality, but more likely indicate protrusion of the cladding in the failed region.

The opposed-dial-gage readings for diameters of the pins were confirmed by use of a continuous readout profilometer. These measurements of ovality and bowing are contained in Table 2 .

Table 2. Bowing and Ovality Measurements by Continuous Readout Profilometer

\begin{tabular}{lll}
\hline Fuel Pin & Bowing, in. & Ovality, in. \\
\hline Top & $0.003-0.004$ & 0.0005 over fueled region \\
Middle & $0.003-0.004$ & 0.0005 over fueled region \\
Bottom & $0.000-0.001$ & 0.0008 near bottom of fueled region \\
\hline
\end{tabular}

Neutron Radiography

Neutron radiographs of the top and bottom fuel pins obtained from exposures in the ORR facility are shown in Fig. 10. Details of the fuel pin components are evident to various degrees. The thermowell (top pin) and tungsten spacers at each end of the fuel columns are delineated, and pellet interfaces are discernible in the fueled region of the top pin but not in the bottom pin. 


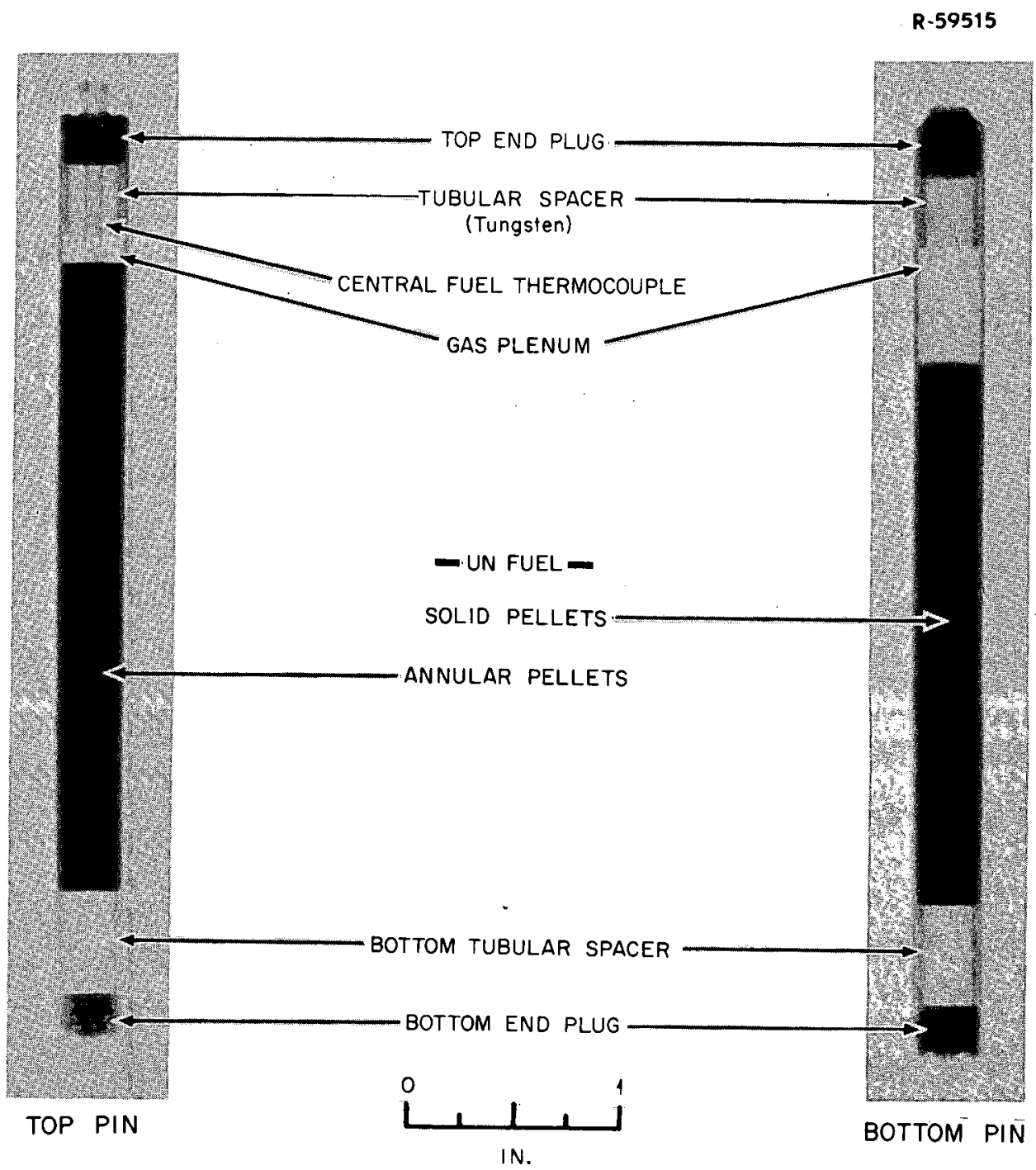

Fig. 10. Neutron Radiograph of Two Fuel Pins of Capsule UN-3.

FISSION GAS ANALYSIS

The two unfailed fuel pins (top and bottom) were punctured in the gas plenum regions and the collected gases analyzed. Low oxygen and nitrogen contents showed that the gas samples were not contaminated by air. Results were as follows: 
Gas recovered, $\mathrm{cm}^{3}$, STP

${ }^{85} \mathrm{Kr}$ activity, dis $\mathrm{min}^{-1} \mathrm{~cm}^{-3}$

$\begin{array}{ll}\frac{\text { Top Pin }}{1.3} & \frac{\text { Bottom Pin }}{3.9} \\ 4.84 \times 10^{9} & 2.31 \times 10^{10}\end{array}$

Adjusting the volume of gas recovered and ${ }^{85} \mathrm{Kr}$ activity for burnup differences (reported under "Fuel Burnup") between the two pins, the ${ }^{85} \mathrm{Kr}$ activity per cubic centimeter for the bottom pin is 4 times that for the top pin, but the volume ratio between the gas recovered from the two pins is only 2.5 to 1 . Therefore, we conclude that the bottom pin ran hotter than the top pin, causing greater gas release. Detailed analyses of the gases are reported in Table 3.

Table 3. Analyses of Gas Recovered from Top and Bottom Fuel Pins of Capsule UN-3

\begin{tabular}{|c|c|c|c|c|c|}
\hline \multirow{2}{*}{ Gas } & \multicolumn{2}{|c|}{ Total Recovered Gas, vol \% } & \multirow{2}{*}{$\begin{array}{l}\text { Fission Gas } \\
\text { Is otope }\end{array}$} & \multicolumn{2}{|c|}{ Abundance, vol \% } \\
\hline & Top Pin & Bottom Pin & & Top Pin & Bottom Pin \\
\hline $\mathrm{H}_{2}$ & 1.9 & 0.3 & ${ }^{130} \mathrm{Xe}$ & & 0.02 \\
\hline $\mathrm{He}$ & 75.9 & 12.0 & ${ }^{13}{ }^{1} \mathrm{Xe}$ & 11.3 & 11.1 \\
\hline $\mathrm{CH}_{4}$ & 0.6 & 0.02 & ${ }^{132} \mathrm{Xe}$ & 17.5 & 18.9 \\
\hline $\mathrm{H}_{2} \mathrm{O}$ & 2.4 & 0.3 & $133 \mathrm{Xe}$ & 1.3 & $<0.1$ \\
\hline $\mathrm{HC}^{\mathrm{a}}$ & 0.8 & & ${ }^{134} \mathrm{Xe}$ & 31.6 & 30.4 \\
\hline $\mathrm{N}_{2}+\mathrm{CO}$ & 1.9 & 0.3 & ${ }^{136} \mathrm{Xe}$ & 38.7 & 39.6 \\
\hline $\mathrm{O}_{2}$ & 0.3 & $<0.01$ & & & \\
\hline Ar & $(0.02)$ & 2.4 & ${ }^{82} \mathrm{Kr}$ & 4.8 & \\
\hline $\mathrm{CO}_{2}$ & 0.3 & 0.04 & ${ }^{83} \mathrm{Kr}$ & 20.6 & 13.9 \\
\hline $\mathrm{Xe}$ & 13.9 & 74.8 & ${ }^{84} \mathrm{Kr}$ & 38.8 & 27.3 \\
\hline $\mathrm{Kr}$ & 1.4 & 9.9 & ${ }^{85} \mathrm{Kr}$ & 10.0 & 7.2 \\
\hline Unidentified & 0.6 & & ${ }^{86} \mathrm{Kr}$ & 25.8 & 51.6 \\
\hline
\end{tabular}

$a_{\text {Hydrocarbons other than methane. }}$ 
SECTIONING AND METALLOGRAPHY

Top Fuel Pin

This pin was sectioned as shown in Fig. 1l. A longitudinal metallographic specimen was prepared from section A which included parts of pellets 6 and 7 as well as the end of the central thermocouple. Metallographic examination disclosed no deleterious effects from the presence of the central thermowell; an occasional globule of metal about $10 \mu \mathrm{m}$ in diameter was noted along the inner surface of the annular pellet that

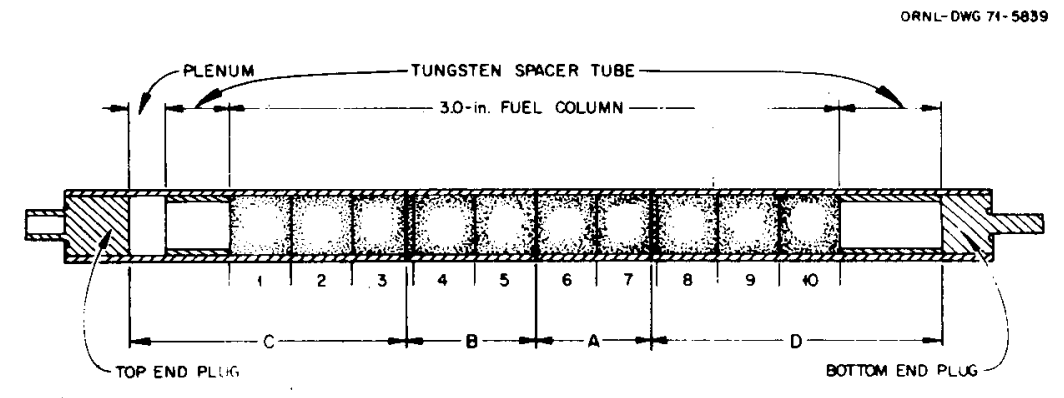

Fig. 1l. Sectioning Diagram of Top Fuel Pin from Capsule UN-3.

contained the the thermowell. The microstructures of the $\mathrm{W}-25 \% \mathrm{Re}$ cladding on opposite sides of the pin are compared in Fig. 12. Apparently, one side of the pin operated at a higher temperature than the other, as evidenced by the comparative degree of recrystallization.

The cladding on the other sections was slit longitudinally to allow recovery of the fuel pellets for various tests. Some of the pellets broke longitudinally during sectioning of the cladding. Figure 13 shows section $C$ after slitting with the central thermowell in place in the pellets. Metallographic examination of the fuel pellets revealed no change in grain size, and the pellets had not sintered together. The microstructure of the fuel at the outside, midradius, and inside regions of the pellets, Fig. 14, shows that the grain size was uniform across the wall of the fuel pellets, and the grain boundaries were decorated with fission gas bubbles. The larger cavities within the grains represent fabrication 

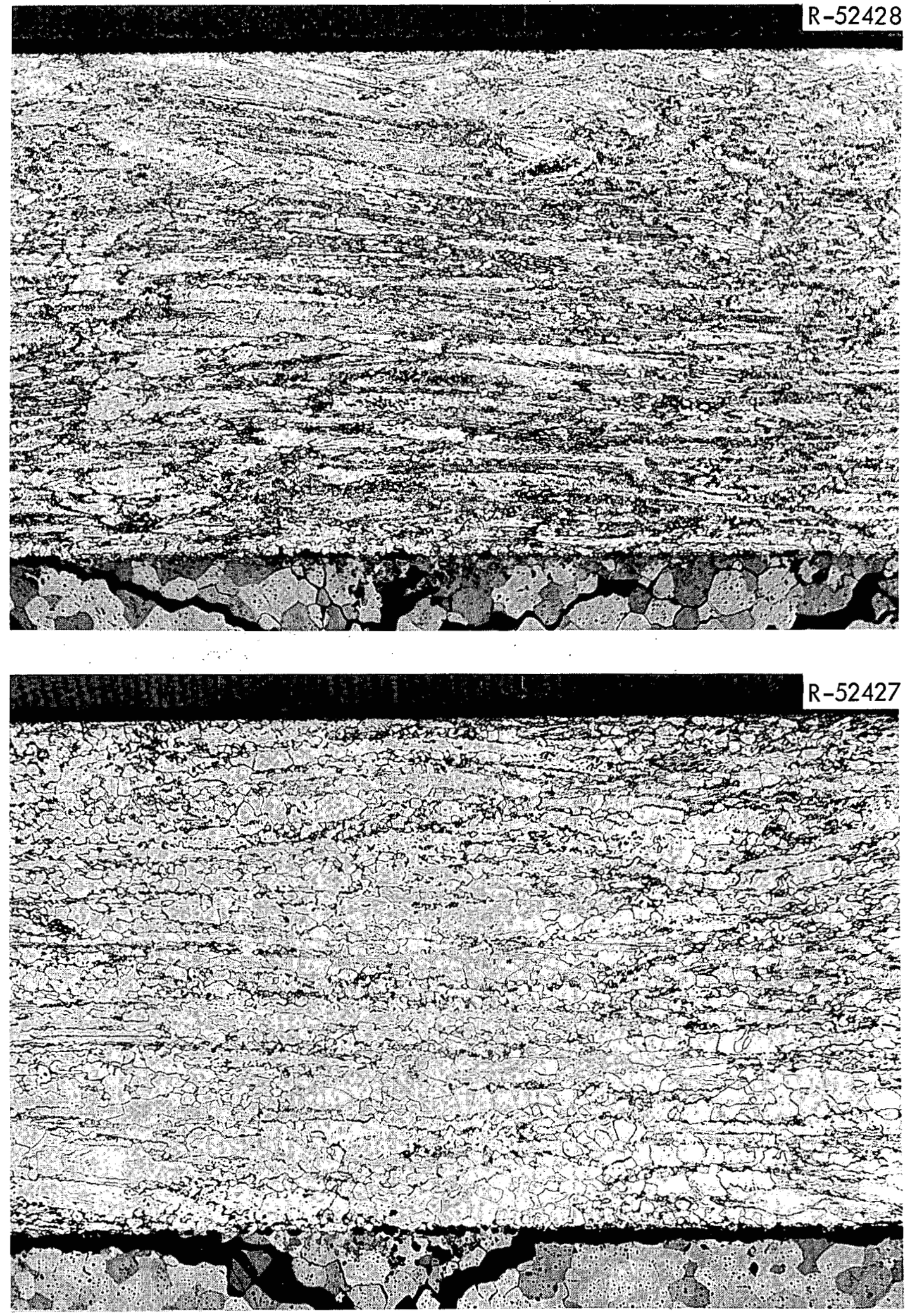

Fig. 12. Appearance of Cladding from Opposite Sides of Top Fuel Pin, Capsule UN-3. Etched. 100×. 


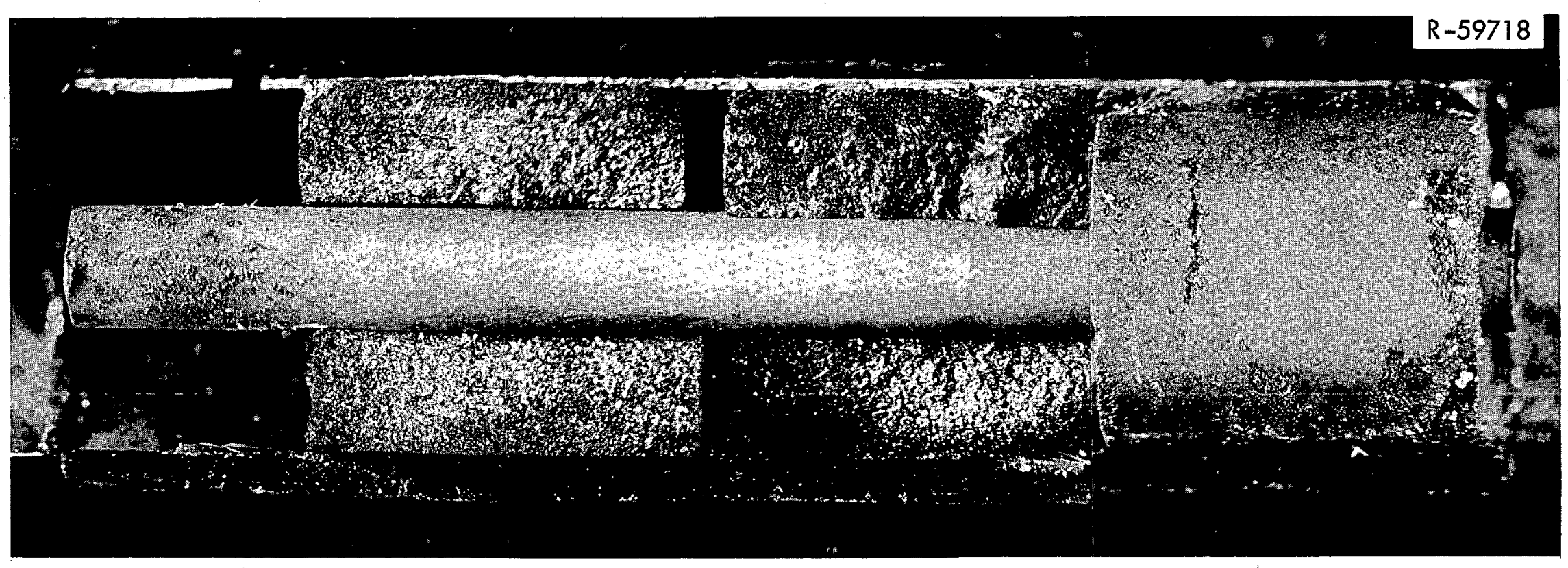

Fig. 13. Portions of Pellets 1 and 2 and Intact Pellet 3 with Thermowell in Place, Top Fuel Pin, Capsule UN-3. 7X. 


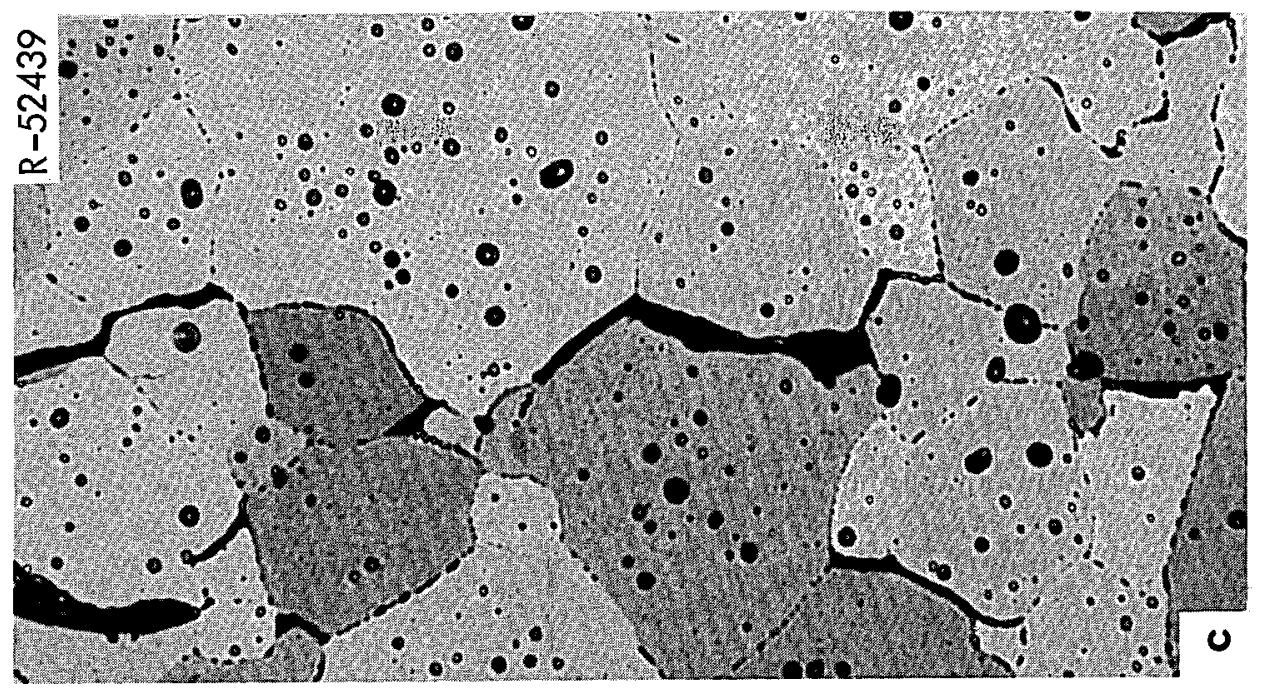

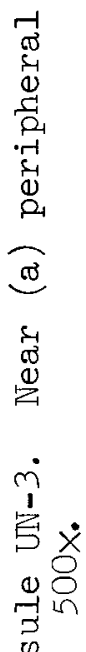

क्ष

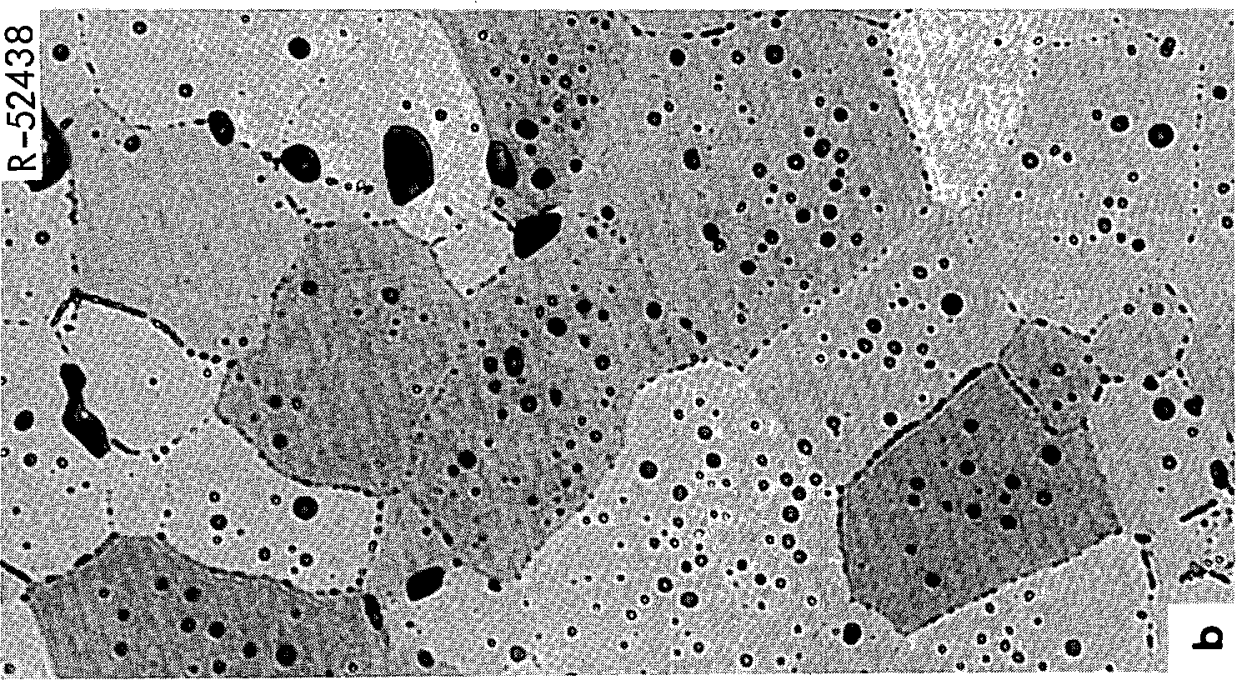

它

里䇺

A.

峁告

일

छึ

क्षे क्ष

诂出

范

क.

म 岇

马

究星

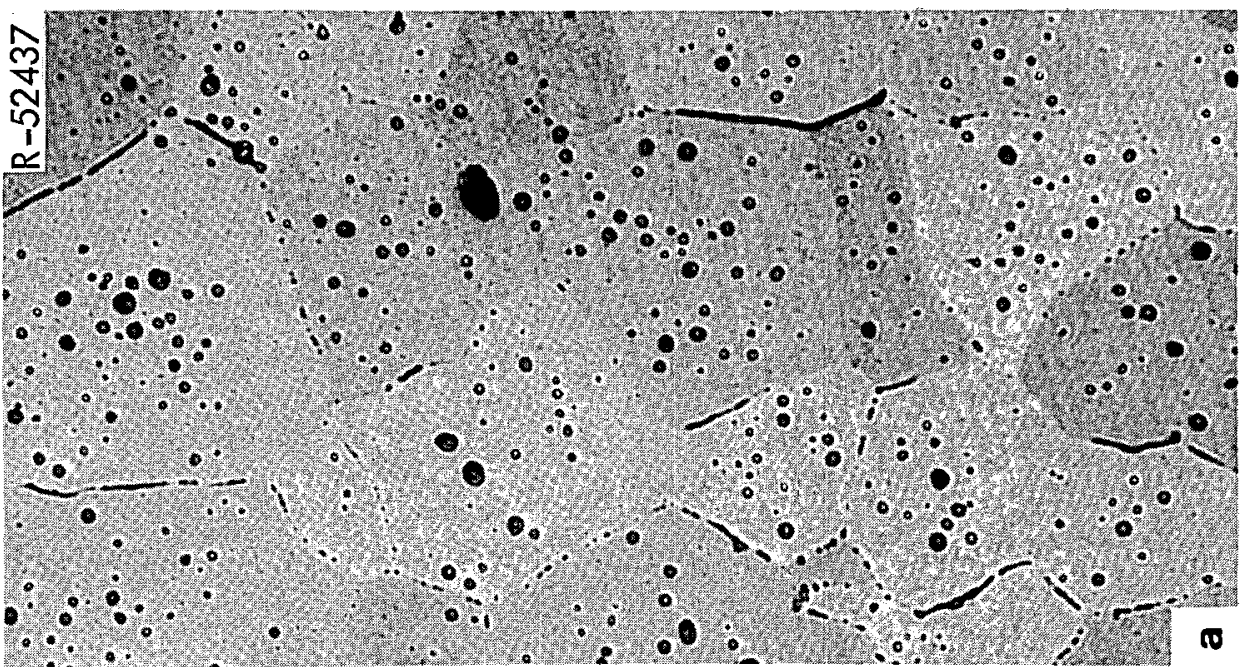

屿

40

ป శ્జ

द्व.

\& 2

屯.

웡

वु

. 몀

등

o

म्न 
porosity. Although some grain boundary separation was apparent in the outer surface region of the fuel pellet, a rather severe degree of grain boundary separation was noted in the inner surface region. Examination of an unirradiated archive pellet showed that the fuel had a tendency for grain boundary separation, as shown in Fig. 15.

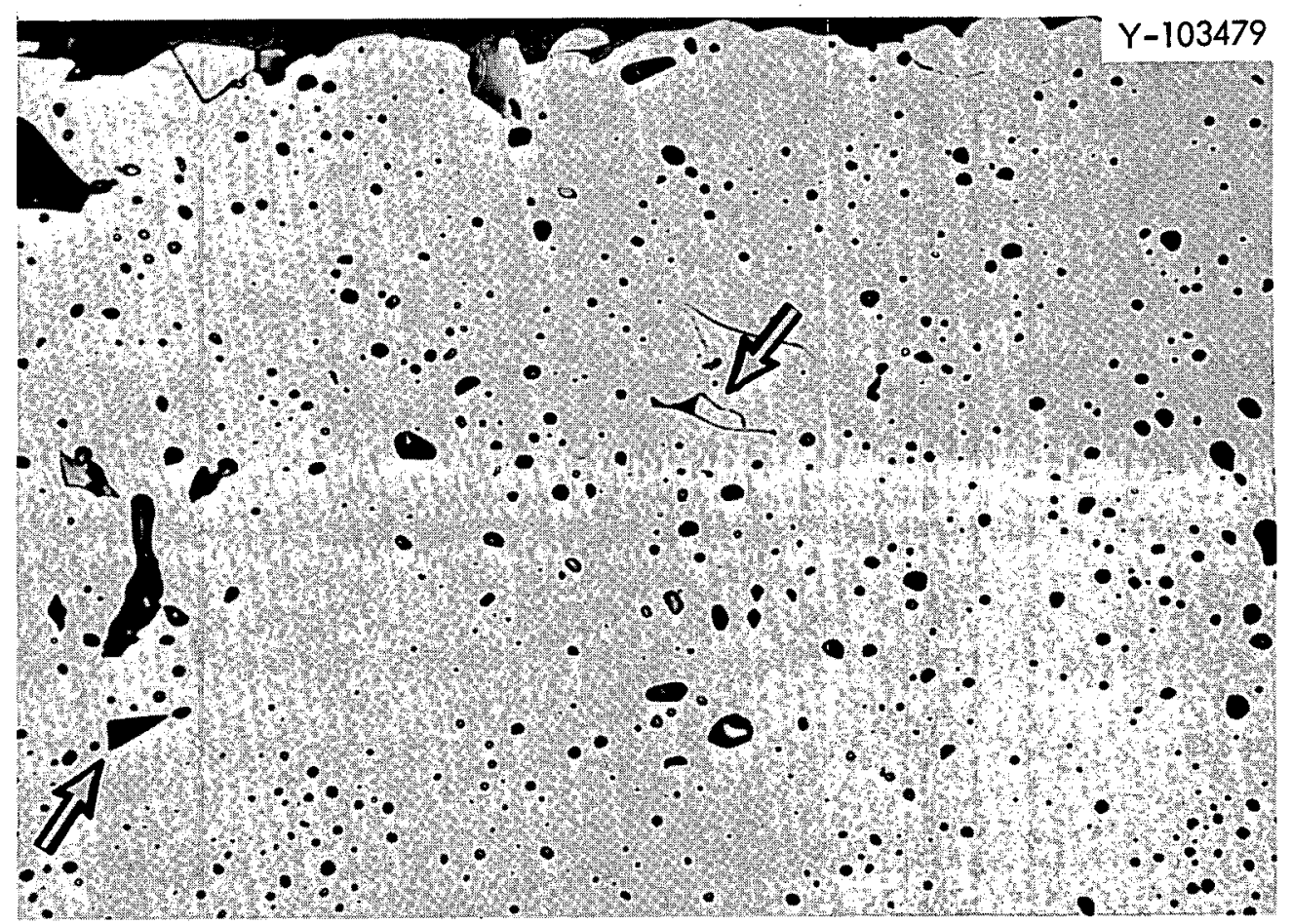

Fig. 15. Appearance of Unirradiated Archive UN Pellet for Top Fuel Pin, Capsule UN-3. This area is at the outer surface of the pellet; note grain boundary separation and occasional missing grain corner (arrows). As polished, 500x. Reduced 12\%.

The general metallographic appearance of this fuel pin is summarized in Fig. 16. There was no evidence of any gross chemical incompatibility between the UN fuel and the $W-25 \%$ Re cladding, although a general intergranular penetration of the cladding occurred to a maximum depth of $20 \mathrm{\mu m}$. (See upper left detail of Fig. 16). Examination of the fuel-cladding interface also showed that the fuel was in intimate contact with the cladding during irradiation; several regions were noted where grains of fuel had separated from the periphery of the pellet during cooldown and remained attached to the cladding. 


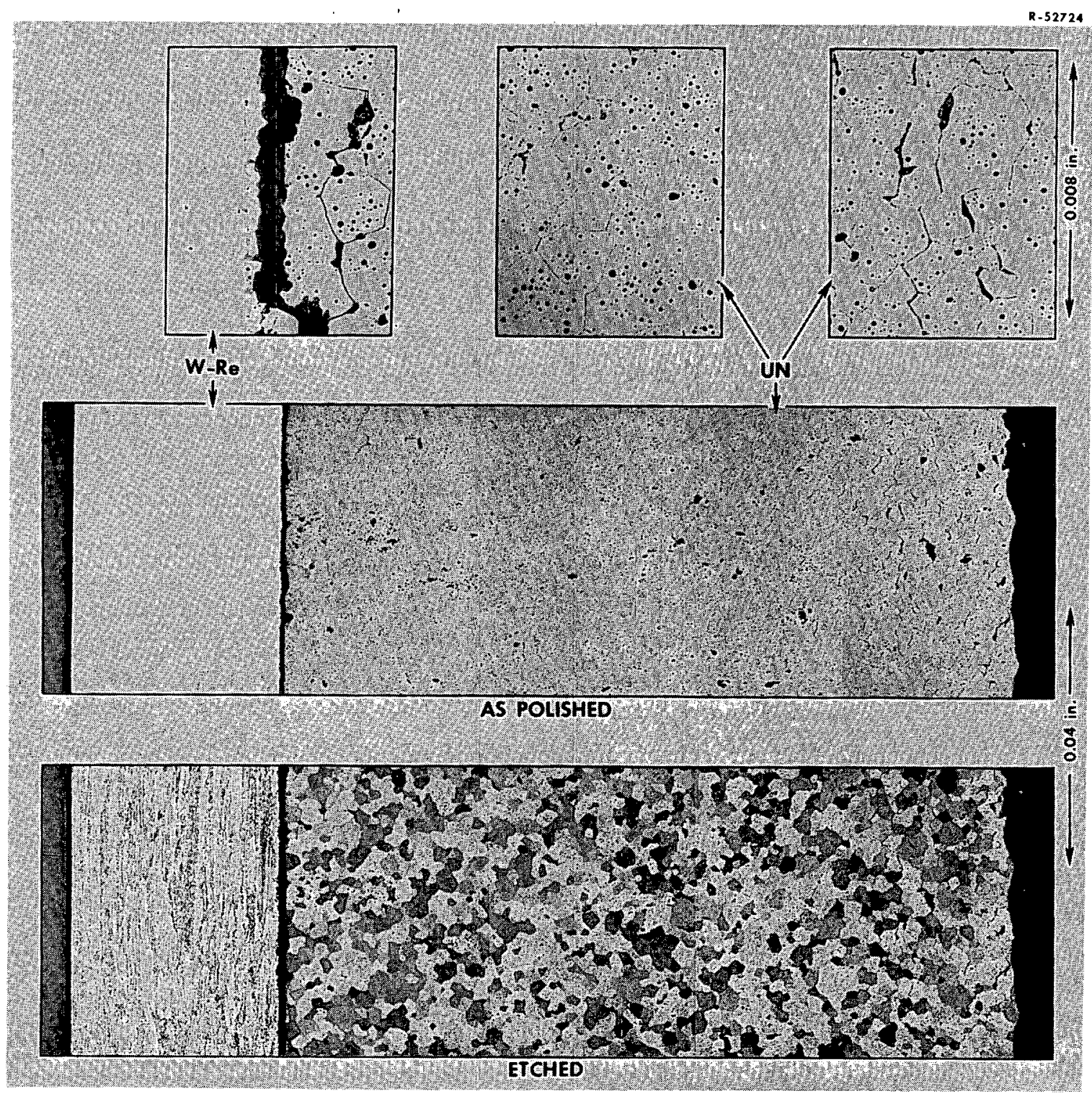

Fig. 16. Typical Microstructural Details from a Longitudinal section Through the Top Fuel Pin of Capsule UN-3.

\section{Middle Fuel Pin}

The cladding on this pin was slit twice longitudinally, about $180^{\circ}$ between the slits. The UN fuel pellets were intact and in intimate contact with the tungsten-lined T-11l cladding. Unreacted NaK was found in the plenum space above the fuel column, and white oxide was evident throughout the interior of the pin. The conditions in this pin are 
shown in Fig. 17. The lower view shows the interior of the cladding with its tungsten liner. In addition to the major crack that admitted NaK into the pin, a number of circumferential and longitudinal cracks were observed in the tungsten liner. Also, the fuel was bonded to the tungsten liner in the lower half of the fuel column. The upper view shows the ten fuel (UN) pellets still in place in the other half of the cladding. At the location of the major crack in the cladding, the fuel appeared to have been eroded away. The UN expanded to fill available space and replicated honing scratches that were on the tungsten liner of the cladding. Fuel pellet interfaces were easily visible in the top portion of the fuel column but virtually undetectable in the lower portion.

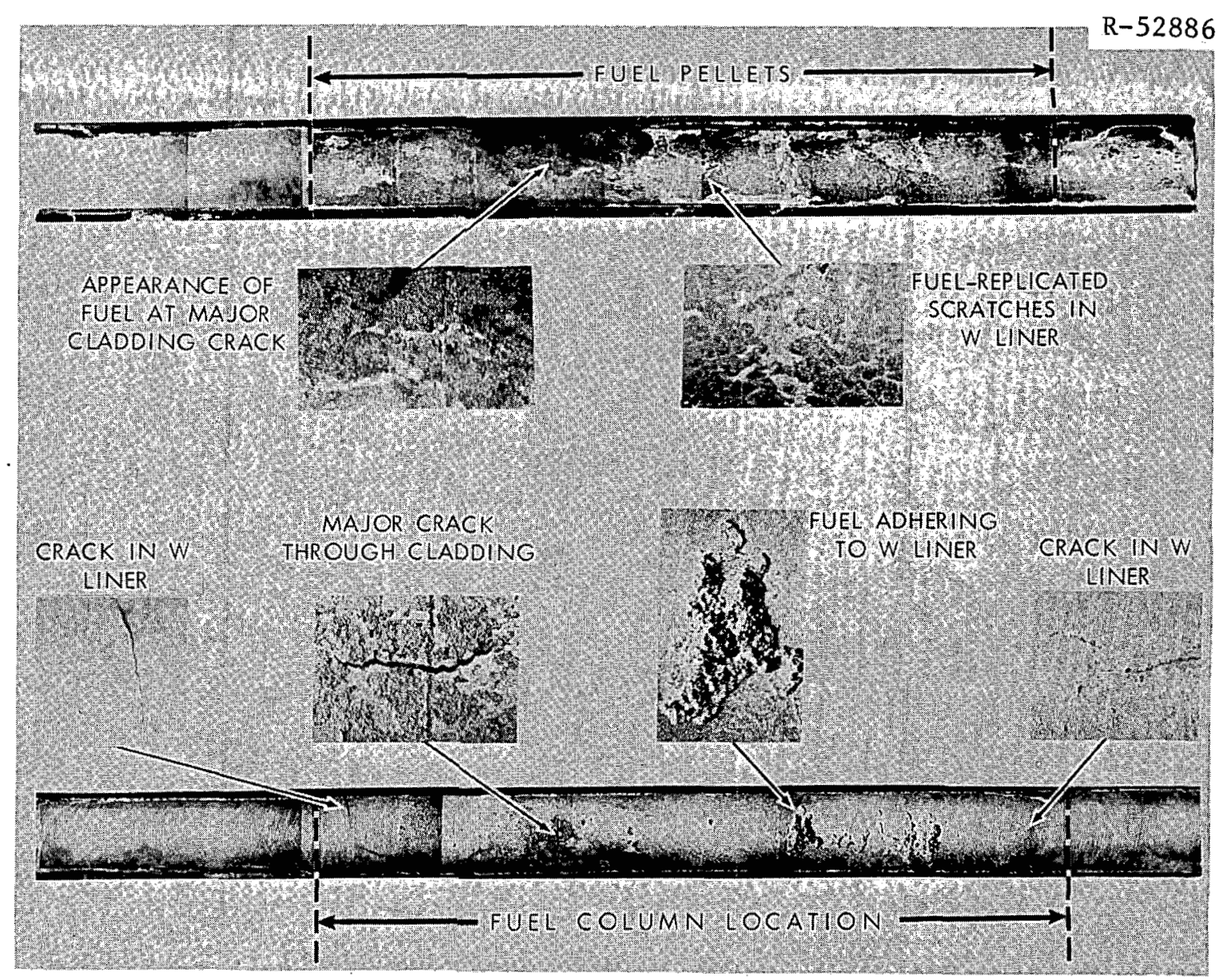

Fig. 17. Middle Fuel Pin of Capsule UN-3 after Longitudinal Slitting of the Cladding and Separation of the Cladding Halves. Top of fuel pin is on left side. 
When the UN pellets were removed from the cladding, a shoulder was visible on the bottom pellet as shown in Fig. 18. The thickness of the shoulder is $9 \mathrm{mils}$, and the diameter is about $240 \mathrm{mils}$, showing that the UN extruded into the bottom tungsten spacer. Since the tungsten spacer at the top end of the fuel column moved freely when the pin was slit open, we conclude that the UN initially expanded to fit tightly in the cladding in the central region, and subsequent swelling of the UN in the lower portion of the column was accommodated by axial expansion into the bottom tungsten spacer.
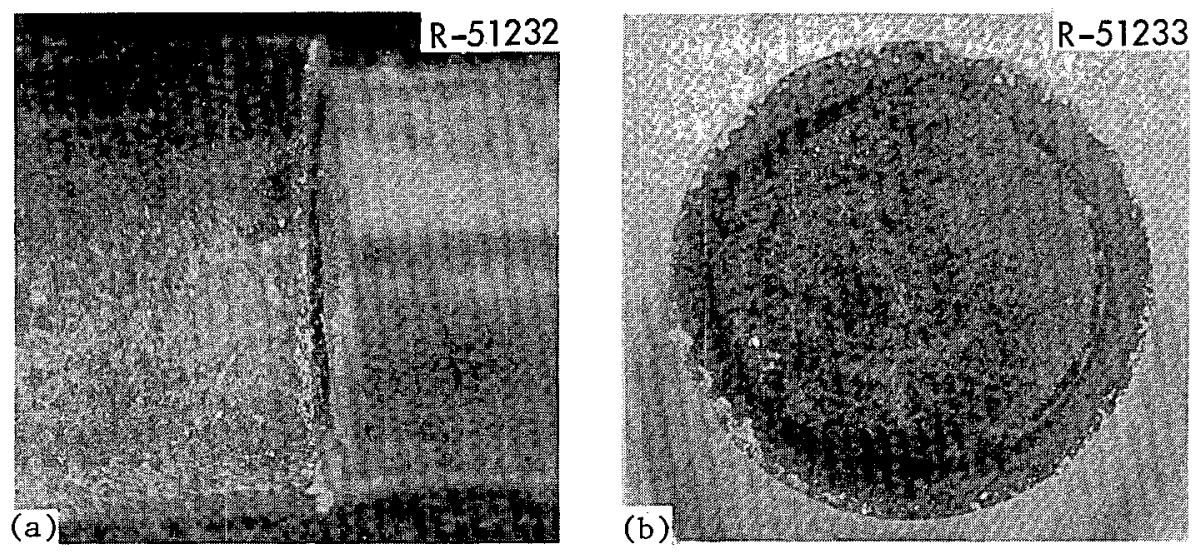

Fig. 18. Shoulder on Bottom UN Pellet, Middle Fuel Pin, Capsule UN-3. (a) Side view, (b) end view. 7x. Reduced 10.5\%.

The middle pin cladding was sectioned as shown in Fig. 19. Sections $A, C, E, G$, and I were used as metallographic specimens. Examination of section $A$, taken through the gas plenum region, showed no evidence of grain growth nor any significant changes in the microstructure of either the T-1Il or tungsten relative to the unirradiated archives. However, a fine intermittent precipitate on grain boundaries and grain corners, revealed only after etching, was noted in the cladding but not in the archives.

The results of the examination of sections through two failed regions (sections $C$ and $E_{1}$ ) are shown in Figs. 20 and 21. Fractures in the T-111 cladding were primarily intergranular, but a few short transgranular fractures were noted in a shallow inner surface region of the T-lll. The intergranular fractures in both the tungsten and T-1il appear to be preceded by spherical cavities. Cavities were found also at the interface between tungsten and T-lll. 
DWG 70-1951

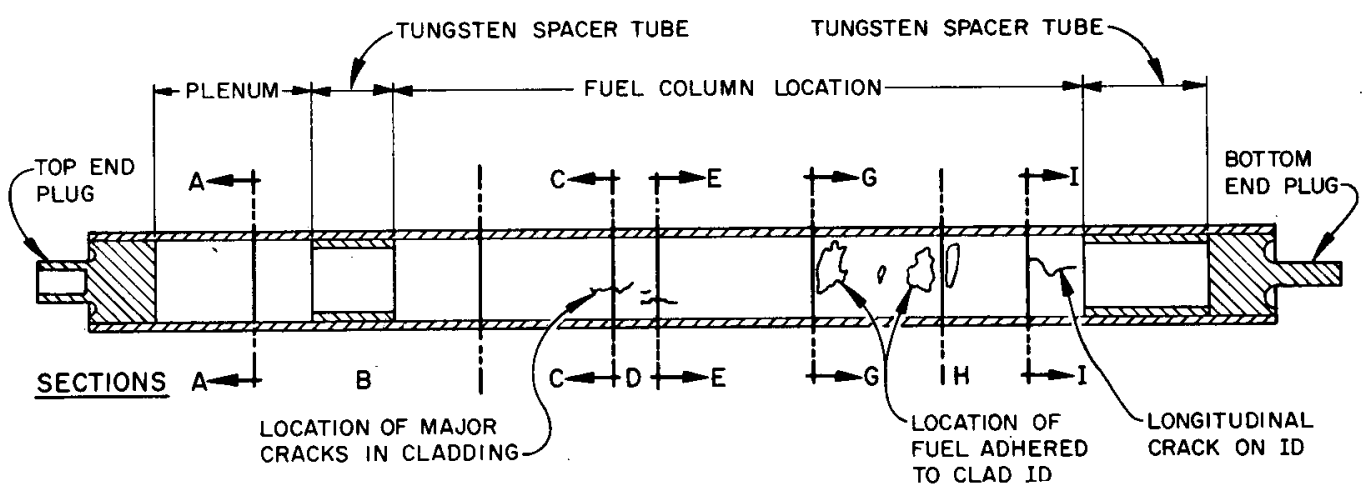

Fig. 19. Sectioning Diagram for Cladding of Middle Fuel Pin of Capsule UN-3.

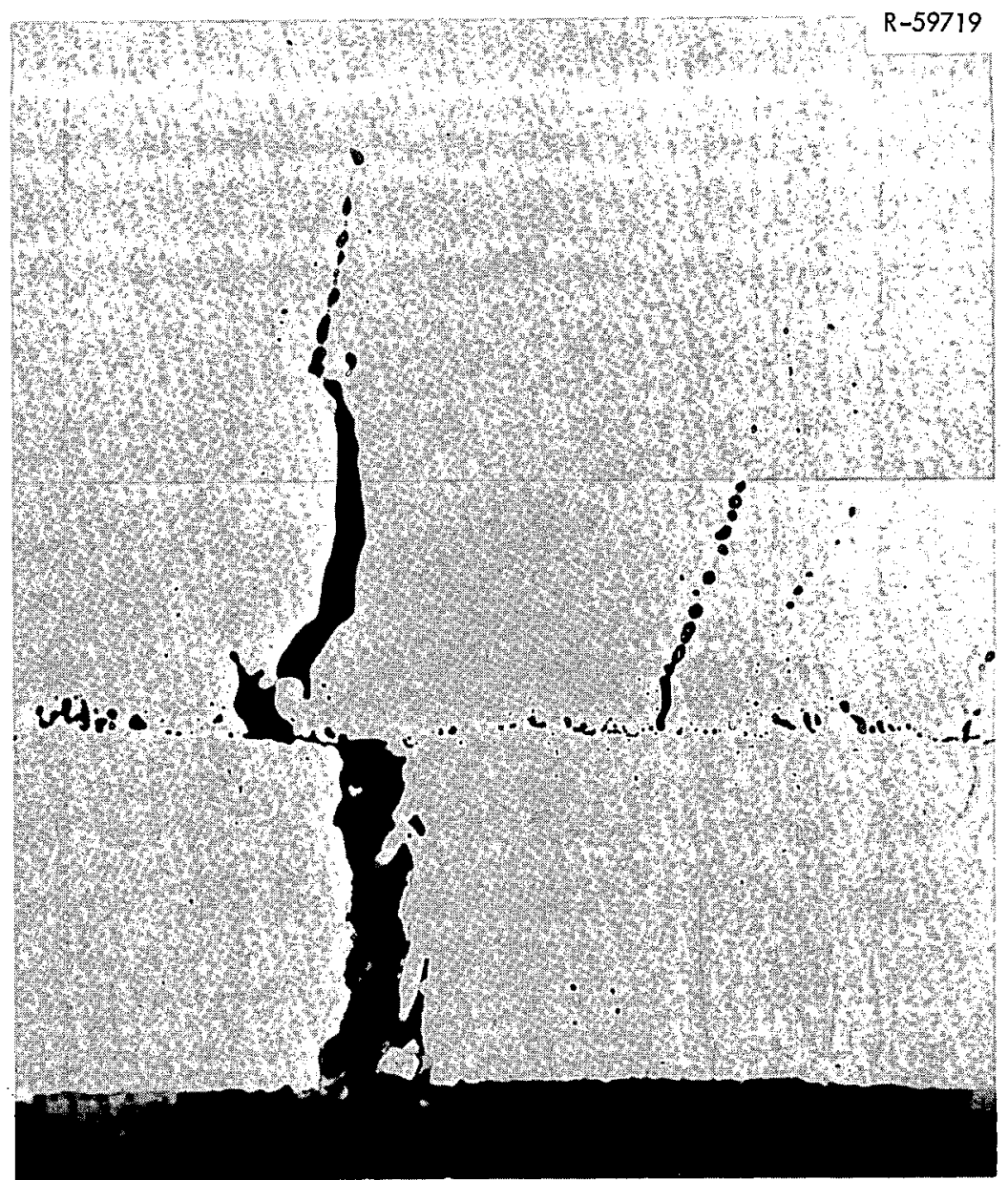

Fig. 20. Appearance of an Area from Section C. Note the series of voids that precedes the intergranular separation of the T-Ill cladding. As polished. 500x. Reduced 29.5\%. 

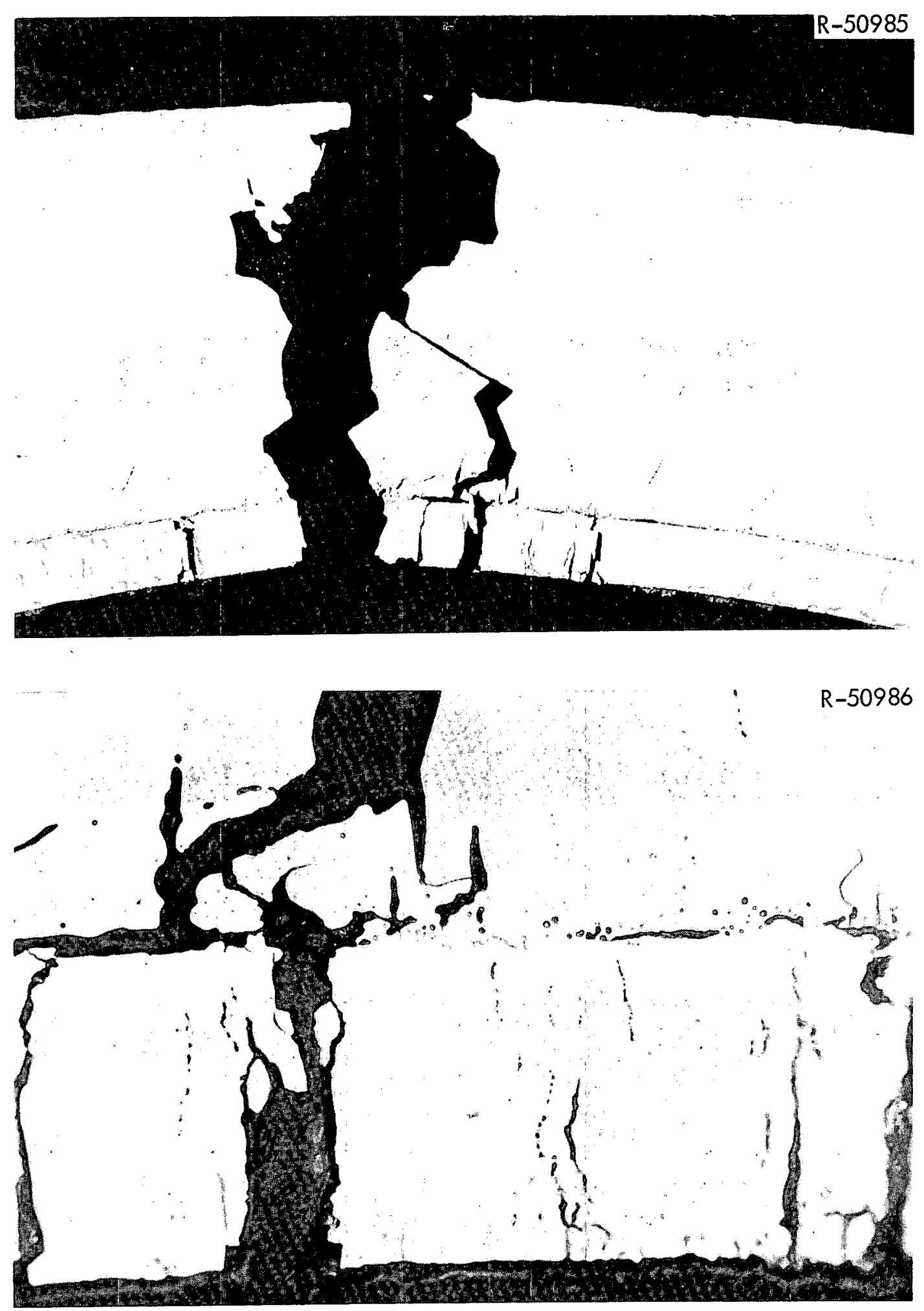

Fig. 21. Appearance of a Failed Region in the T-1ll Cladding and Tungsten Liner from Section E of the Middle Pin. (a) Low, 100x, and (b) high, 500x, magnification. As polished. Reduced 3\%. 
Metallographic examination of a section from an unfailed region (section $G$ ) revealed intergranular separations in the T-lll that originated at the inner surface and extended through half the wall thickness, as shown in Fig. 22. Numerous cavities were observed at the interface between tungsten and $\mathrm{T}-11 \mathrm{l}$ and as intergranular cavities in the T-1ll.
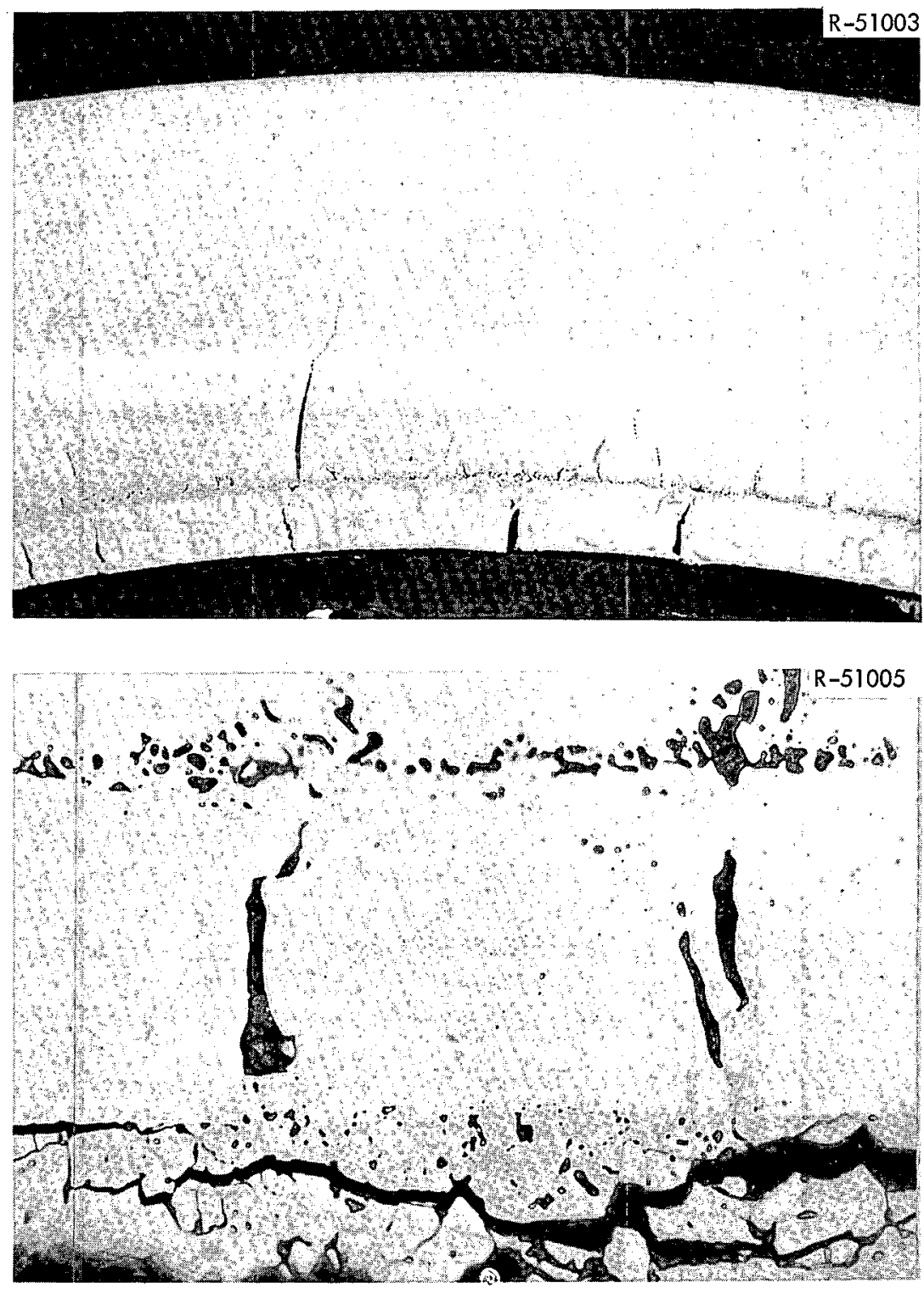

Fig. 22. Appearance of $\mathrm{T}-111 \mathrm{Cladding}$ and Tungsten Liner from Section $G$ of the Middle Fuel Pin. (a) Low, 100x, and (b) high, 500x, magnifications. As polished. Reduced 26.5\%. 
Intergranular separations occurred also in the tungsten liner. A region where the fuel had adhered to the tungsten liner is shown in Fig. 22(b). We noted that not only had the UN bonded with the tungsten, but in some regions the UN had penetrated the tungsten to a depth of about $15 \mu \mathrm{m}$. We also noted the occasional presence of a gray phase in some of the grain-boundary separations in the T-lll and in some of the cavities at the interface between tungsten and $T-111$. This gray phase can be seen also in Fig. $22(b)$.

Bottom Fuel Pin

The bottom fuel pin in this experiment was essentially a duplicate of the middle (failed) pin, both in design and operation. The pin was sectioned as shown in Fig. 23. All fuel pellets were intact, and

ORNL-DWG 71-5838

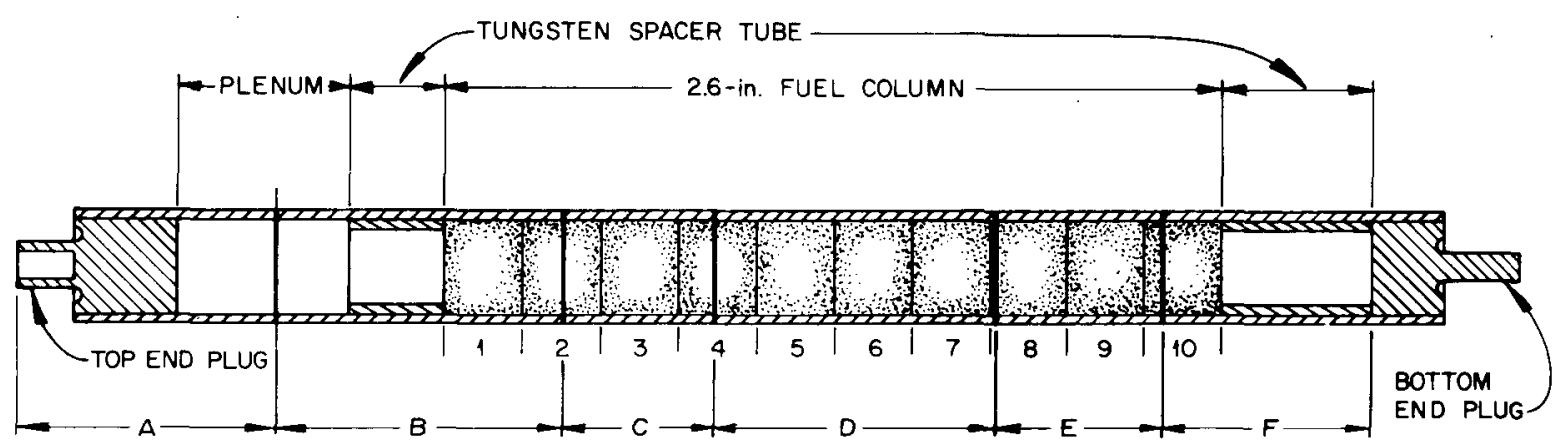

Fig. 23. Sectioning Diagram for Cladding of Bottom Fuel Pin of Capsule UN-3.

matching discolorations were seen on the fuel and the inside surface of the cladding, indicating intimate contact between fuel and cladding during irradiation. No evidence was found to show extrusion of pellets into the tungsten spacers as occurred in the middle pin.

A transverse section is shown in Fig. 24. Cracks and cavities observed in both the tungsten liner and the T-lll cladding were similar to those that led to failure of the middle fuel pin. 


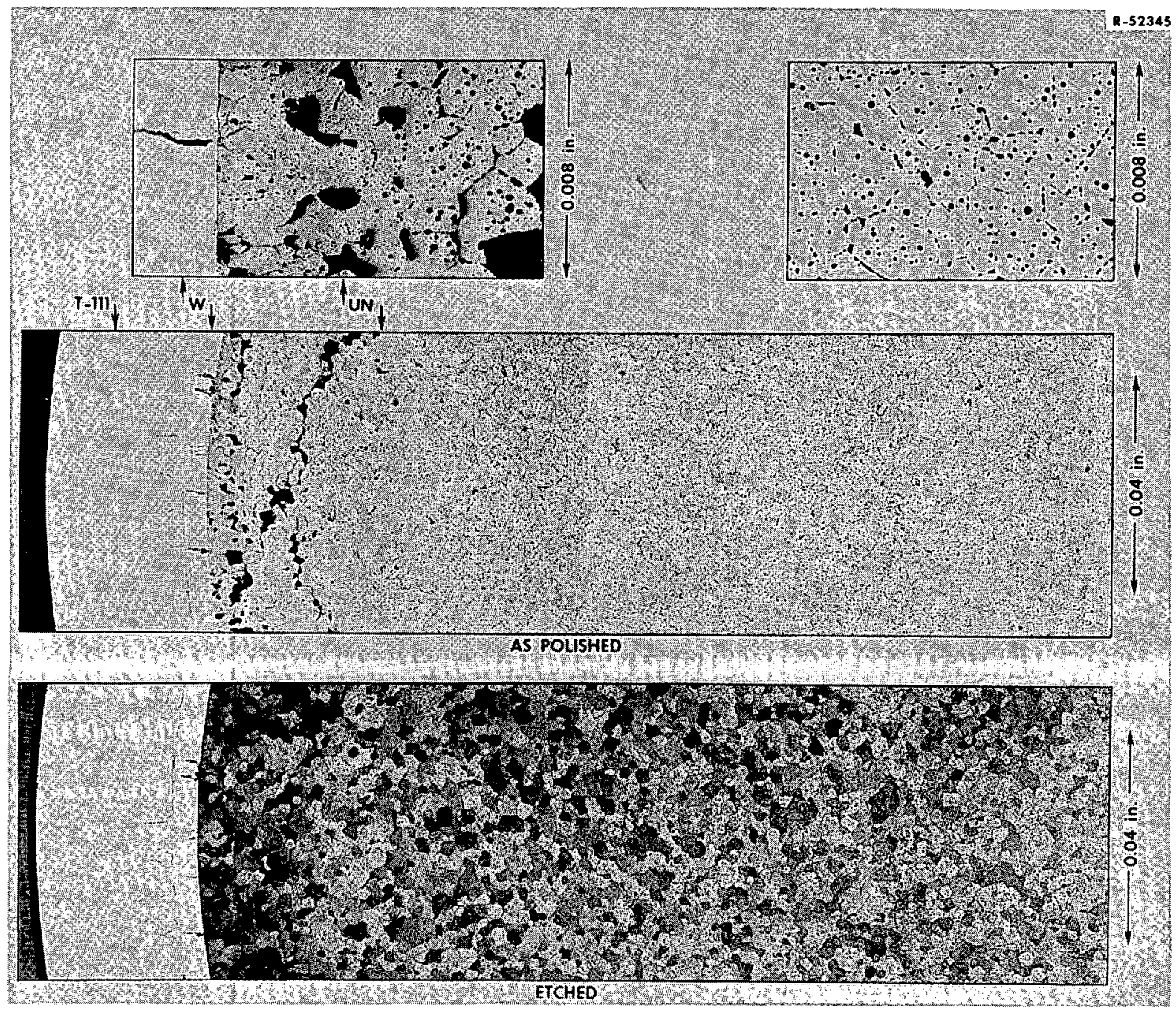

Fig. 24. Typical Microstructural Details from a Transverse Section Through the Bottom Fuel Pin of Capsule UN-3.

\section{FUEL BURNUP}

Design burnup was 1.45 at. \% for the top fuel pin, and 1.75 at. \% for the middle and bottom pins. Radiochemical analyses (for ${ }^{95} \mathrm{Zr},{ }^{137} \mathrm{Cs}$, and ${ }^{144} \mathrm{Ce}$ ) were performed on fuel samples from positions of interest in the three fuel pins. Also, uranium isotopic abundances were determined by mass spectrometry for fuel from the top pin. Burnup values calculated from these analyses are reported in Table 4. Since the burnups calculated from the $\mathrm{Zr}, \mathrm{Ce}$, and $\mathrm{Cs}$ analyses are not well representative of design 
Table 4. Burnup Values for Capsule UN-3

\begin{tabular}{|c|c|c|c|c|c|c|}
\hline \multirow{3}{*}{\multicolumn{2}{|c|}{$\begin{array}{l}\text { Fuel Pin } \\
\text { and Pellet }\end{array}$}} & \multicolumn{5}{|c|}{ Fissions per Initial Heavy Metal Atom, \% } \\
\hline & & \multicolumn{4}{|c|}{ Calculated from } & \multirow{3}{*}{$\begin{array}{r}\text { Design } \\
1.45\end{array}$} \\
\hline & & $\begin{array}{l}\text { Uranium } \\
\text { Is otopic }\end{array}$ & $137 \mathrm{Cs}$ & ${ }^{1.44} \mathrm{Ce}$ & $95 \bar{z} r$ & \\
\hline \multirow[t]{2}{*}{ Top } & 2 & 1.34 & 1.34 & 1.11 & 0.88 & \\
\hline & 5 & 1.48 & 1.44 & 1.25 & 0.98 & \\
\hline \multirow[t]{2}{*}{ Middle } & 2 & & 1.37 & 1.22 & 0.89 & 1.75 \\
\hline & 5 & & 1.00 & 1.20 & 0.88 & \\
\hline Bottom & 4 & & 1.09 & 1.25 & 0.88 & 1.75 \\
\hline
\end{tabular}

conditions in the relationships between the three pins nor with temperatures determined during irradiation, we suggest that the generally more reliable uranium isotopic analysis be accepted. This strongly siggests that design burnups (adjusted for shortened irradiation time) were very nearly achieved.

\section{FUEL SWELLING}

Changes in fuel pellet densities, as determined by immersion techniques, are tabulated in Table 5. The fuel pellets of the middle pin generally decreased more in density than those of the other two pins. Substantial variation in pellet densities (e.g., pellet 4 vs pellets 3 and 5) is unexplained for the middle fuel pin. The average value for density decrease for the pellets in the top pin is not comparable to that for the lower pins, since the pellets in the top pin were fabricated with a central hole for the thermowell. Correlation coefficients for the pellet density changes versus the initial pellet density are 0.43 , 0.69 , and 0 , respectively, for the top, middle, and bottom pins. This indicates less than 50\% chance of correlation of the data for the top pin, fair correlation for the middle pin and none for the bottom pin. Since the middle pin cladding failed and admitted NaK to the pellets, it is unlikely that the correlation coefficient of 0.69 is meaningful. 
Table 5. Density Changes for UN Pellets Irradiated in Capsule UN-3

\begin{tabular}{|c|c|c|c|c|c|}
\hline \multirow{2}{*}{\multicolumn{2}{|c|}{$\begin{array}{l}\text { Pin and } \\
\text { Pellet }\end{array}$}} & \multicolumn{3}{|c|}{ Density of of Theoretical } & \multirow{3}{*}{$\frac{\frac{\Delta p}{\rho_{0}} \times 100}{3.8}$} \\
\hline & & \multirow{2}{*}{$\frac{\begin{array}{c}\text { Preirradiation, } \\
\rho_{0}\end{array}}{95.4}$} & \multirow{2}{*}{$\begin{array}{c}\begin{array}{c}\text { Postirradiation, } \\
P_{i}\end{array} \\
91.80\end{array}$} & \multirow{2}{*}{$\frac{\begin{array}{c}\text { Decrease, } \\
40\end{array}}{3.6}$} & \\
\hline Top & 1 & & & & \\
\hline & 2 & 95.5 & 92.50 & 3.0 & 3.1 \\
\hline & 3 & 95.0 & 91.74 & 3.3 & 3.5 \\
\hline & 4 & 95.3 & 91.14 & 4.2 & 4.4 \\
\hline & 5 & 96.2 & 92.38 & 3.8 & 4.0 \\
\hline & 6 & 95.8 & & & \\
\hline & 7 & 96.1 & & & \\
\hline & 8 & 95.3 & 91.47 & 3.8 & 4.0 \\
\hline & 9 & 95.1 & 91.36 & 3.7 & 3.9 \\
\hline & 10 & 95.0 & 90.75 & 4.2 & 4.4 \\
\hline & & & Average & 3.7 & 3.9 \\
\hline Middle & 1 & 93.4 & 89.54 & 3.9 & 4.2 \\
\hline & 2 & 94.0 & 89.86 & 4.1 & 4.4 \\
\hline & 3 & 93.4 & 90.40 & 3.0 & 3.2 \\
\hline & 4 & 95.5 & 89.55 & 6.0 & 6.3 \\
\hline & 5 & 92.9 & 89.66 & 3.2 & 3.4 \\
\hline & 6 & 95.8 & 89.90 & 5.9 & 6.2 \\
\hline & 7 & 93.3 & 90.14 & 3.2 & 3.4 \\
\hline & 8 & 95.4 & 88.88 & 6.5 & 6.8 \\
\hline & 9 & 92.5 & 90.06 & 2.4 & 2.6 \\
\hline & 10 & 95.5 & 87.51 & 8.0 & 8.4 \\
\hline & & & Average & 4.6 & 4.9 \\
\hline Bottom & 1 & 92.7 & 88.75 & 3.9 & 4.2 \\
\hline & 2 & 93.4 & 90.42 & 3.0 & 3.2 \\
\hline & 3 & 95.5 & & & \\
\hline & 4 & 94.1 & 93.18 & 0.9 & 1.0 \\
\hline & 5 & 93.2 & 91.78 & 1.4 & 1.5 \\
\hline & 6 & 94.3 & 91.01 & 3.3 & 3.5 \\
\hline & 7 & 93.3 & 89.02 & 4.3 & 4.6 \\
\hline & 8 & 95.4 & & & \\
\hline & 9 & 95.1 & & & \\
\hline & 10 & 92.5 & 92.00 & 0.5 & 0.5 \\
\hline & & & Average & 2.5 & 2.6 \\
\hline
\end{tabular}


The release of fission gases from the fuel bodies was low $0.1 \%$ for the top pin and $7.1 \%$ for the bottom pin). Fission gas retention led to swelling by accumulation of fission gas bubbles at the grain boundaries, as seen in Fig. 25. The large cavities within the grains were fabrication porosity. The porosity at the grain boundaries is shown

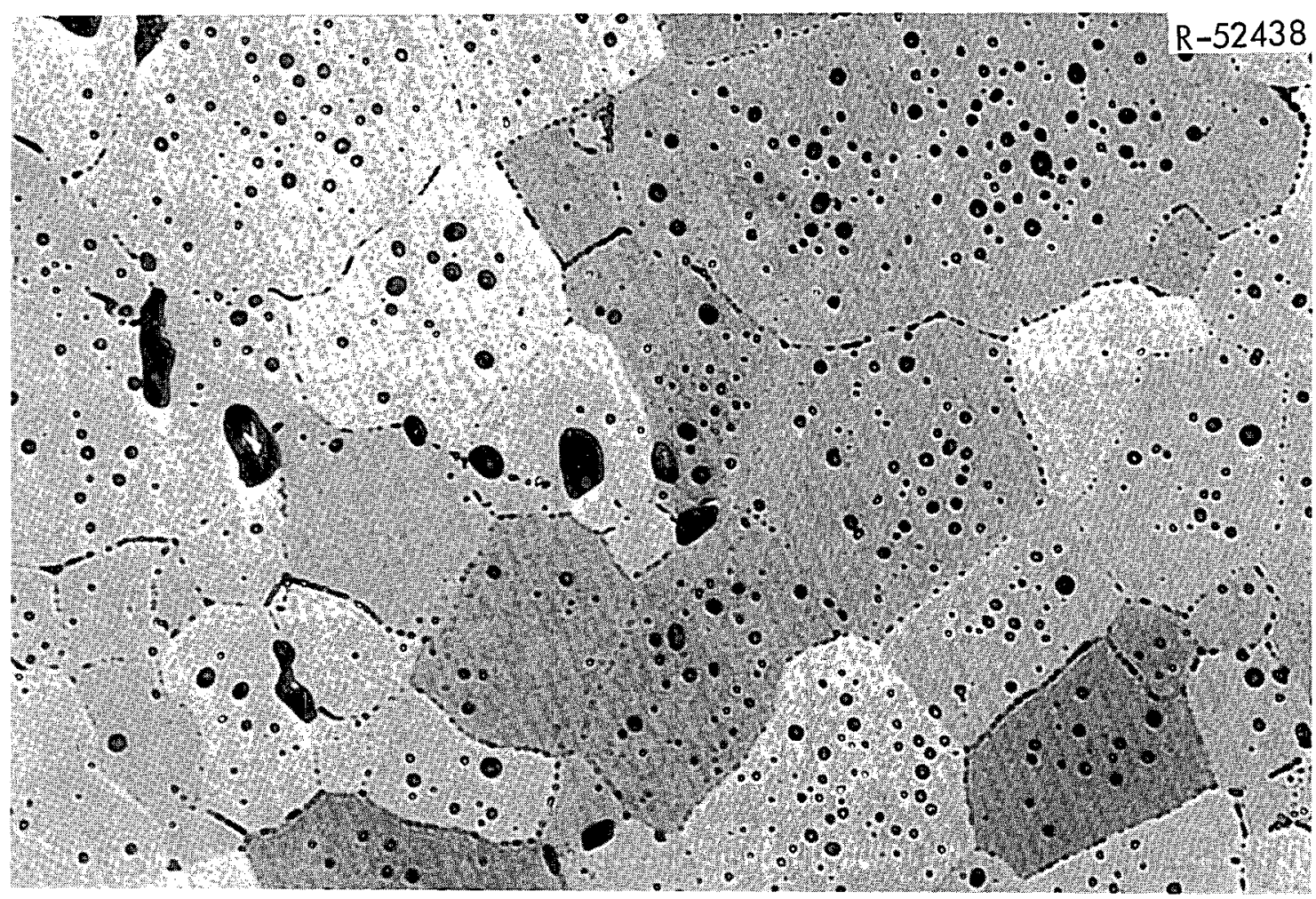

Fig. 25. Metallographic Appearance of Irradiated UN Fuel from the Bottom Pin of Capsule UN-3. 500x.

more clearly in Fig. 26 by transmission electron microscopy of replicas of fractured UN surfaces. The intergranular fracture shows coalescence of bubbles of fission gas at grain boundaries. The transgranular fracture shows small bubbles of fission gas in the grain as well as larger cavities that we believe to be fabrication porosity. The coalescence of the fission gases at the grain boundaries forces the grains apart and produces substantial swelling of the fuel, although the fission gases are not released in large quantity from the fuel body. It has been established 

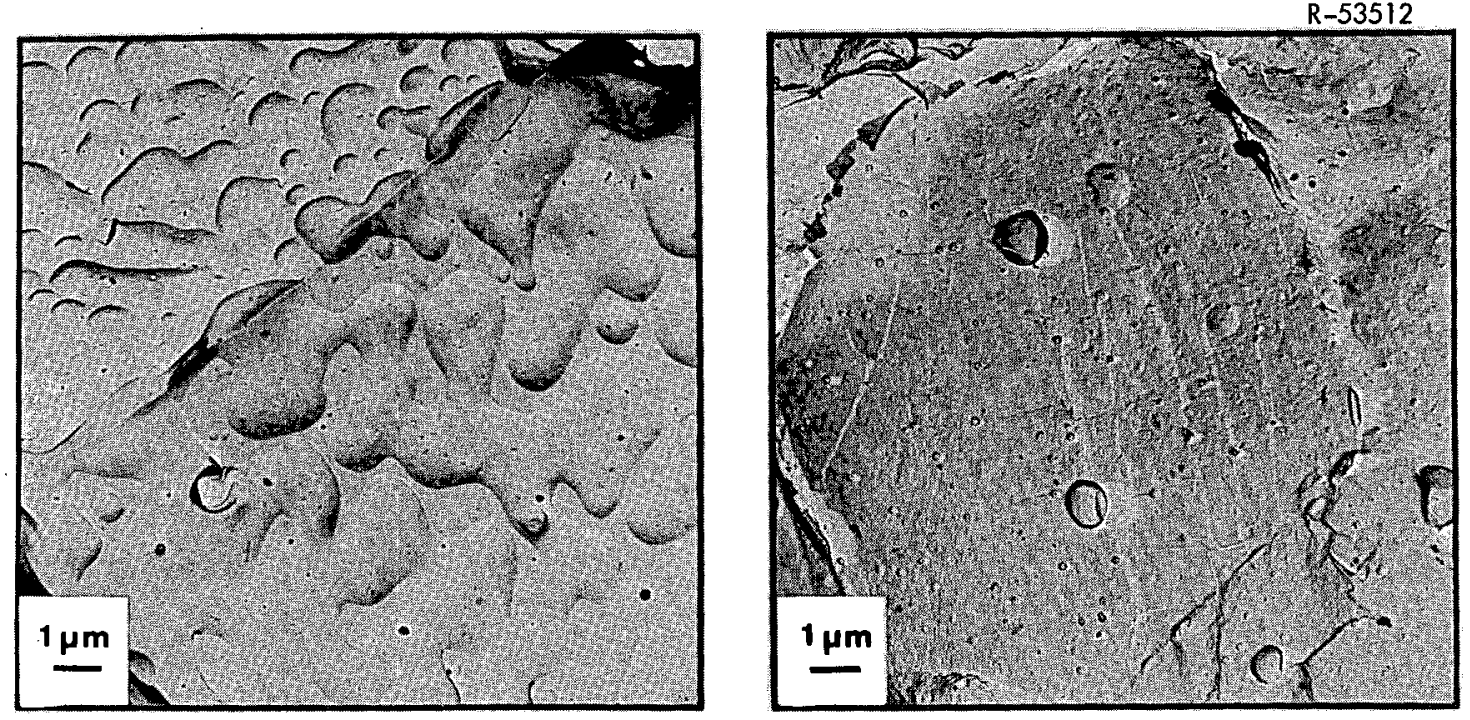

Fig. 26. Fractographic Surfaces from the Central Region of a UN Fuel Pellet from Bottom Fuel Pin, Capsule UN-3. (a) Intergranular and (b) transgranular. Carbon replica shadowed with chromium.

that elimination of grain boundaries by use of single-crystal UN effectively reduces volume increases during irradiation. ${ }^{10}$ other investigators showed similar results by use of large-grained or porous UN fuel. ${ }^{11}$

\section{EXAMINATION OF T-III CLADDING}

\section{Nitrogen in Cladding}

Two sections of cladding were chosen from the middle fuel pin for Kjeldahl nitrogen determinations. One section included about a $7 / 16-i n$. length of the unfailed half of the cladding, from $11 / 8$ to $19 / 16 \mathrm{in}$. from the top of the pin, and the other section was the next 7/16 in. down from the first section. Both sections were in the fueled region of

${ }^{10} \mathrm{~S}$. C. Weaver, K. R. Thoms, and V. A. DeCarlo, Trans. Amer. Nucl. Soc. $\underline{\underline{12}}(2), 54 \dot{7}$ (1969).

$\overline{11}_{R}$. F. Hilbert et al., Trans. Amer. Nucl. Soc. 13, 102 (1970). 
the cladding; however, the first section described was coincident with the extreme upper end of the fuel column. The net nitrogen contents were 34 and $70 \mathrm{ppm}$, respectively, for the upper and lower sections as described above. These values indicate an increase in average nitrogen content over that of the unirradiated T-1ll, which contained from 11 to $56 \mathrm{ppm} \mathrm{N}$.

\section{Microhardness}

We measured the microhardness across the wall of the T-lll cladding on three sections from the middle (failed) pin and compared these values with an archive sample. The cladding sections came from the gas plenum region, the failed region, and near the bottom of the fuel column; the results aire shown in Fig. 27. The sections from both the gas plenum and from near the bottom of the fuel column were harder than the archive and showed an increase in hardness across the wall of the cladding as the

ORNL-DWG 70-2988R

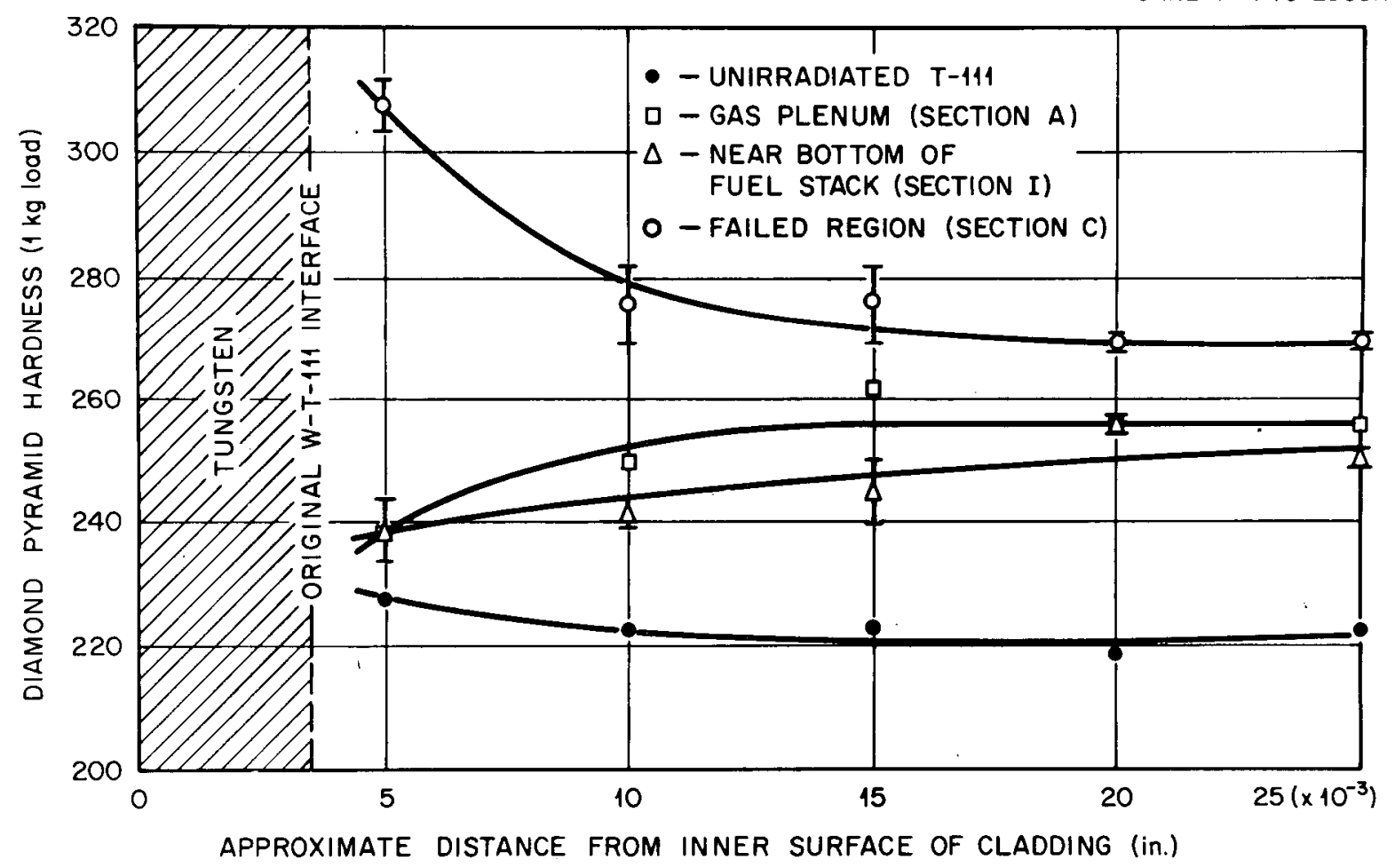

Fig. 27. Microhardness of Cladding of Middle Pin from Capsule UN-3. 
outer surface was approached. A marked increase in hardness was measured in the section from the failed region, but in contrast to the other two sections the maximum hardness occurred at the inner surface region.

Grain Size

The grain size was 6 times larger in the failed region of the middle fuel pin than in the gas plenum region. There was an average of only seven grains across the cladding in the failed region. The grain diameters were as follows: unirradiated material, $0.022 \mathrm{~mm}$; section $A$, $0.017 \mathrm{~mm}$; section C, $0.102 \mathrm{~mm}$; section I, $0.022 \mathrm{~mm}$. (See Fig. 19 for location of sections.)

Electron Microprobe

Some of the cracks in the T-1Il near the tungsten liner and cavities at the cladding-liner interface contained a material of low optical reflectivity, as shown in Fig. 22. Microprobe analysis showed this material to be rich in hafnium. On areas slightly smaller than the electron beam diameter, the hafnium content was 65\%; therefore, this figure is to be taken as a lower limit of hafnium concentration. Similar hafnium concentrations were found alongside all cracks in the tungsten liner. Spectral analyses of the hafnium-rich areas failed to detect any additional elements. However, our present detector system does not enable us to analyze for nitrogen. Except where the UN fuel had been extruded into cracks in the tungsten liner, there was no evidence of uranium in the cracks or grain boundaries of the tungsten or T-11l. No movement of the tungsten-T-1Il interface, as a result of high temperature operation, was detected. Analysis of the interface regions failed to detect the existence of diffusion gradients. Consequently, it is highly unlikely that the cavities in the vicinity of the cladding-liner interface are the result of the Kirkendall effect. 
Scanning Electron Microscopy

Since the irradiated T-lll cladding from both middle and bottom pins was brittle at room temperature, replicas were readily obtained from fresh fractures. Scanning electron micrographs of a replica taken from cladding fractured longitudinally near the failed region of the middle pin are shown in Fig. 28. The large variation in grain size between

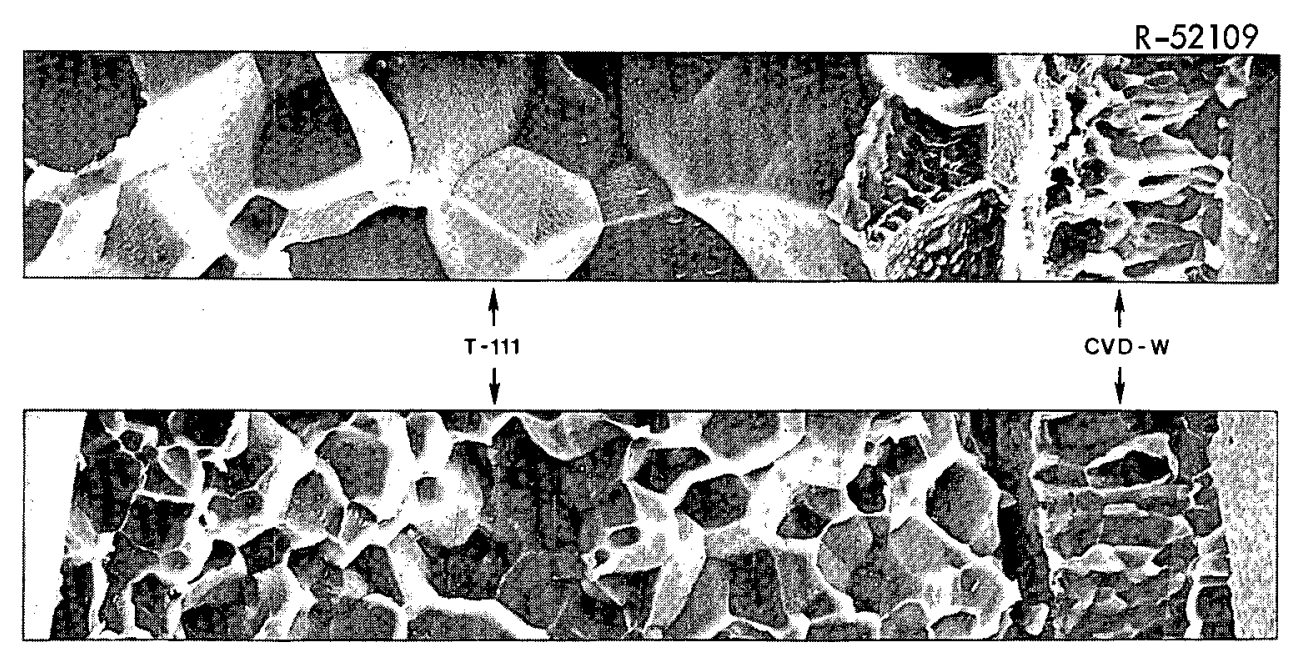

Fig. 28. Scanning Electron Micrographs of Two Fracture Surfaces about $1 \mathrm{~cm}$ Apart. The larger grained region (a) was near the failed region of the cladding. Plastic replica, gold shadowed. About 200x. Reduced $16 \%$.

regions about $1 \mathrm{~cm}$ apart, shown in Fig. 28, indicates that localized hot spots developed in the cladding during irradiation. Large grain boundary cavities in the T-1ll near the cladding-liner interface are apparent in Fig. 28(a). Higher magnification micrographs of the finer grained region in Fig. 28(b) also revealed grain boundary cavities. Grain boundary cavities were observed throughout the cladding thickness; the radius of the cavities, in the range of $10^{-5}$ to $10^{-4} \mathrm{~cm}$, decreased from the inner to outer surface of the cladding. The density of grain boundary cavities was estimated to be about $5 \times 10^{6} / \mathrm{cm}^{2}$ of grain boundary area. Numerous grain boundary cavities were present in the tungsten liner, which also fractured intergranularly as shown in Fig. 29. 


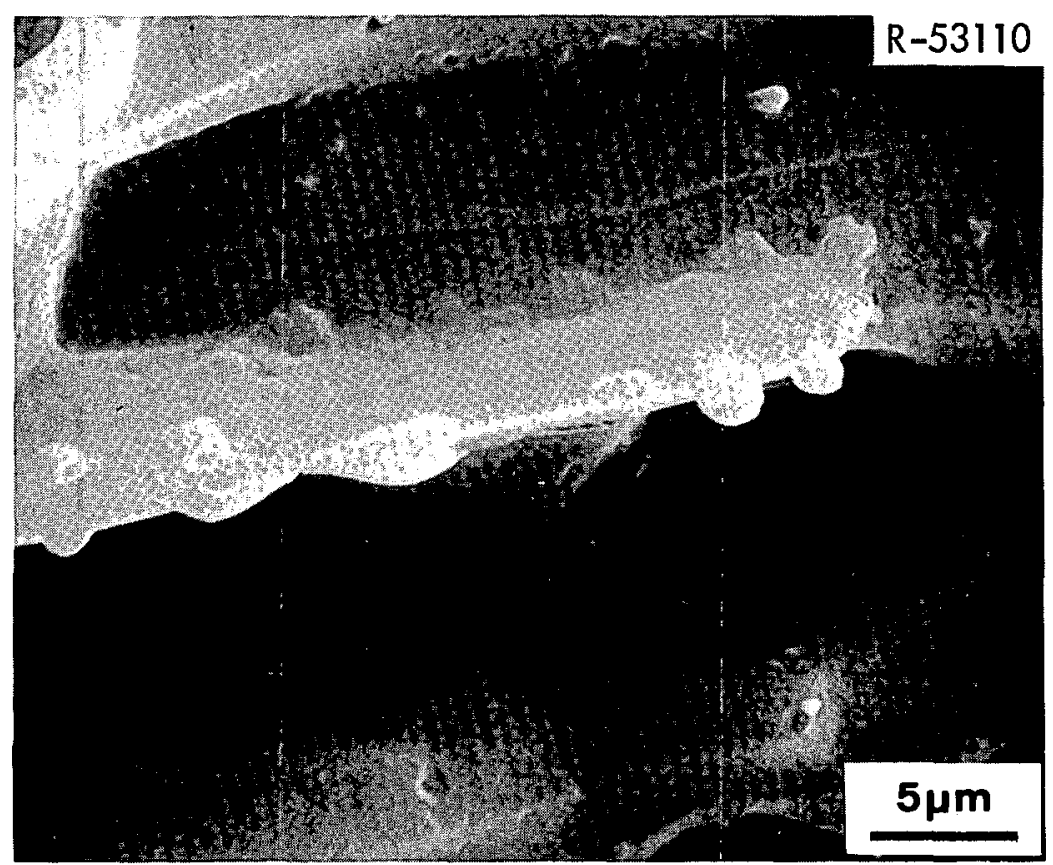

Fig. 29. Grain Boundary Cavities in CVD Tungsten Liner as Revealed by Scanning Electron Microscopy Image of a Plastic Replica of a Fracture Surface. Gold shadowed.

Discussion of Cavity Formation and Intergranular Fracture

The mechanical properties of T-lll under conditions of neutron irradiation at elevated temperatures have not been reported. Stephenson and McCoy $^{12}$ have shown in out-of-reactor testing that $\mathrm{T}-111$ at temperatures in the range 1200 to $1650^{\circ} \mathrm{C}$ exhibits good ductility under creep conditions, with fracture strains in excess of 20\%. The fractures were generally transgranular, and grain boundary cracks or cavities were not observed. Consequently, we propose a mechanism whereby the radiation environment promotes the formation of grain boundary cavities in T-lll.

An obvious mechanism is the embrittlement of $\mathrm{T}-1 \mathrm{ll}$ by formation of grain boundary gas bubbles. Hyam and Sumner ${ }^{13}$ have demonstrated that

${ }^{12}$. L. Stephens on and H. E. McCoy, Jr., "The Creep-Rupture Properties of Some Refractory Metal Alloys, III. Comparative Mechanical Behavior of Some Tantalum-Base Alloys," J. Less-Common Metals 15(4), 415-424' (August 1968).

${ }^{13}$ E. D. Hyam and G. Sumner, p. 323 in Radiation Damage in Solids, Vol. 1, International Atomic Energy Agency, Vienna, 1962. 
gas bubbles under an imposed tensile stress expand so that the sum of the normal stress and the pressure inside the bubble is balanced by the surface tension restraint. However, above a critical stress given by

$$
\sigma_{c}=0.77 \gamma / r_{0}
$$

where

$$
\begin{aligned}
& y=\text { the specific surface energy, } \\
& r_{0}=\text { the equilibrium radius of a bubble in the absence of an } \\
& \text { internal stress, }
\end{aligned}
$$

the bubble will grow indefinitely. Thus, above a critical stress, bubbles will experience runaway growth leading to crack formation.

If this mechanism is to be acceptable to explain T-1ll cladding failure, it is necessary to demonstrate that sufficient inert gas bubbles can be nucleated and that the magnitude of the tensile stress necessary to cause runaway growth of these bubbles is reasonable. The usual gaseous impurities, oxygen, nitrogen, and hydrogen, are relatively soluble in T-III and form compounds after exceeding the solubility limits. The most likely source of insoluble gas is nitrogen, which has a high $(n, \alpha)$ cross section with fast neutrons. ${ }^{14}$ Although nitrogen concentrations in T-11l cladding are not known with great certainty, initial values range from 11 to $56 \mathrm{ppm}$. Chemical analyses from the unfailed region of cladding near the top of the middle pin show nitrogen contents in the range 34 to $70 \mathrm{ppm}$, with the higher nitrogen content in the specimen closer to the cladding failure region. This trend in nitrogen pickup by the T-lll is consistent with the microhardness measurements, which suggest that considerably higher nitrogen contents may exist in regions of the cladding near the failure. Inouye and Leitnaker ${ }^{15}$ have shown that the equilibrium nitrogen pressure over UN at $1500^{\circ} \mathrm{C}$ is about $5 \times 10^{-6}$ torr.

${ }^{14}$ I. R. Birss, J. Nucl. Mater. 34, 241 (1970).

${ }^{15} \mathrm{H}$. Inouye and J. M. Leitnaker, "Equilibrium Nitrogen Pressures and Thermodynamic Properties of UN," J.Amer. Ceram. Soc. 5I (1), 6-9 (January 1968). 
Moreover, Inouye ${ }^{16}$ reports that the nitrogen solubility in $\mathrm{T}-111$ at $1400^{\circ} \mathrm{C}$ in an atmosphere of $4.7 \times 10^{-6}$ torr $\mathrm{N}_{2}$ is about $300 \mathrm{ppm}$. Consequently, nitrogen pickup by the T-11l cladding under the operating conditions in this experiment is highly likely if the tungsten liner is not an effective protective barrier. Many cracks in the tungsten liner contained UN fuel extrusions. This is evidence that the cracks existed at temperature during irradiation. Moreover, the fuel extrusions show that the fuel exerted considerable stress on the cladding. The intergranular failure of the CVD tungsten liner under the operating conditions of the middle pin is not unexpected. Stiegler, Farrell, and co-workers ${ }^{17,18}$ have clearly established that grain boundary gas bubbles form in CVD tungsten on annealing at temperatures above $1400^{\circ} \mathrm{C}$. The mechanism of failure - that is, the linking up of grain boundary bubbles under tensile stress - is the same as we are proposing to have taken place in the T-lll cladding.

Thus, although the final nitrogen contents in the T-lll near the failure region are unknown, it is assumed that a time-average nitrogen content of 100 ppm was present. This nitrogen content is sufficient to lead to $10^{15}$ atoms of helium per cubic centimeter. The calculations are shown in the Appendix.

It is now necessary to show that a helium content of $10^{15}$ atoms $/ \mathrm{cm}^{3}$ is sufficient to give a reasonable density of critical bubbles. Substitution of 2000 psi for $\sigma_{c}$, which is considerably lower than the 5000 psi necessary to cause failure in $6000 \mathrm{hr}$ in $\mathrm{T}-1 \mathrm{ll}$ out-of-reactor, and $\gamma=1000 \mathrm{ergs} / \mathrm{cm}^{2}$ in Eq. (1) gives $5 \times 10^{-6} \mathrm{~cm}$ for $r_{0}$. The number of

${ }^{16} \mathrm{H}$. Inouye, Metals and Ceramics Div. Ann. Progr. Rept. June 30, 1971, ORNL-4770, p. 109.

${ }^{17} \mathrm{~K}$. Farrell, J. T. Houston, and A. C. Schaffhauser, "The Growth of Grain Boundary Gas Bubbles in Chemically Vapor Deposited Tungsten," pp. 363-390 in Proceedings of the Conference on Chemical Vapor Deposition of Refractory Metals, Alloys, and Compounds, Gatlinburg, Tennessee, September 12-14, 1967, ed. by A. C. Schaffhauser, American Nuclear Society, Hinsdale, Illinois.

${ }^{18} \mathrm{~J}$. O. Stiegler, K. Farrell, B.T.M. Loh, and H. E. McCoy, "Nature of Creep Cavities in Tungsten," ASM (Am. Soc. Metals) Trans. Quart.

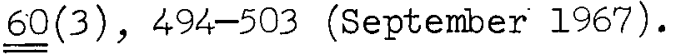


helium atoms in an equilibrium bubble can be calculated from the relationship

$$
P_{0}=2 \gamma / r_{0},
$$

where $P_{\circ}$, the equilibrium pressure in the bubble, assuming the perfect gas law can be written as

$$
P_{0}=3 n k T / 4 \pi r_{0}{ }^{3}
$$

with $\mathrm{n}=$ number of atoms,

$\mathrm{k}=$ Boltzmann constant,

$\mathrm{T}=$ temperature in ${ }^{\circ} \mathrm{K}$.

Thus,

$$
\mathrm{n}=8 \pi \mathrm{r}_{0}^{2} \gamma / 3 \mathrm{kT}
$$

For $r_{0}=5 \times 10^{-6} \mathrm{~cm}, \gamma=1000 \mathrm{ergs} / \mathrm{cm}^{2}$, and $\mathrm{T}=1673^{\circ} \mathrm{K}, \mathrm{n}=8 \times 10^{5}$. Consequently, the number of equilibrium bubbles of $r_{0}=5 \times 10^{-6} \mathrm{~cm}$ that can be supported by $10^{15}$ helium atoms $/ \mathrm{cm}^{3}$ is about $10^{9}$ bubbles $/ \mathrm{cm}^{3}$.

Experimentally, we observe about $5 \times 10^{5}$ bubbles $/ \mathrm{cm}^{2}$ of grain boundary area. If bubbles form exclusively at grain boundaries in the T-lll, this corresponds to about $10^{\circ}$ bubbles $/ \mathrm{cm}^{3}$ since the grain boundary area per cubic centimeter ${ }^{19}=2 \mathrm{~N}_{\mathrm{L}}=200 \mathrm{~cm}^{2} / \mathrm{cm}^{3}$. The number of grain boundary intersections per unit length of test line, ${ }^{N} L$, in material with grain size of $0.1 \mathrm{~mm}$ is $100 / \mathrm{cm}$.

Thus, assuming that all of the helium is segregated near grain boundaries, we have shown that the observed number of cavities could have existed as equilibrium bubbles of the critical size (500 $\AA$ ) for breakaway growth under a tensile stress of 2000 psi. For catastrophic failure by growth of grain boundary cavities it is not necessary, however, that all bubbles exceed the critical radius. Helium could have segregated at the grain boundaries as a result of prior segregation of

\footnotetext{
${ }^{19}$ C. S. Smith and L. Guttman, Trans. AIME 221, 344 (1961).
} 
nitrogen. Nitrogen segregation is likely since microprobe analyses have shown high hafnium contents at grain boundaries, and HfI is one of the most stable nitrides known.

So far, we have shown, using equilibrium considerations, that sufficient helium bubbles can be formed in T-lll under the conditions of this experiment. The cladding temperature of about $1400^{\circ} \mathrm{C}$ corresponds to $0.53 \mathrm{~T}_{\mathrm{m}}$, where $\mathrm{T}_{\mathrm{m}}$, the melting temperature, is about $3250^{\circ} \mathrm{K}$. Consequently, sufficient mobility, particularly in the presence of irradiationinduced point defects, is expected to permit the aggregation of gas atoms into bubbles. The operating temperature may have been higher than $0.53 \mathrm{~T}$, since cladding hot spots were indicated by metallography.

Further observations, particularly using transmission electron microscopy and specimens from regions of lower operating temperature, are necessary before this mechanism of helium embrittlement, demonstrated to be possible, can be established as the main cause of the intergranular failure of $T-11 l$ fuel cladding.

\section{CONCLUSIONS}

\section{Performance of UN Fuel}

The UN fuel performed satisfactorily in all three pins. The fission gas release was only $0.1 \%$ at $1380^{\circ} \mathrm{C}$ (top pin) and $7.1 \%$ at $1500^{\circ} \mathrm{C}$ (bottom pin). Swelling of the fuel was adequately restrained by the cladding and was limited to closing of the as-fabricated 0.005-in. gap between fuel and cladding. There was no gross chemical reaction between the fuel and cladding. Although the fuel and cladding interacted to a depth of about $20 \mu \mathrm{m}$, electron microprobe analysis of the cladding revealed no indications of uranium penetration beyond that depth. Nitrogen released from the UN may have interacted with the T-1ll cladding and led to the degradation of the mechanical properties. 
Top Fuel Pin

The performance of this fuel pin was completely satisfactory, with the $\mathrm{W}-25 \% \mathrm{Re}$ cladding at a temperature of $1300^{\circ} \mathrm{C}$ on the outer surface and the central fuel temperature decreasing from $1380^{\circ} \mathrm{C}$ at the beginning of the test to $1330^{\circ} \mathrm{C}$ at the end of the test. This decrease in temperature difference between the fuel center line and cladding indicates an improved thermal conductance of the fuel pin during operation. This improvement was due to swelling of fuel until it came into intimate contact with the cladding. The fuel pin diameter did not increase during testing, and no significant chemical reaction occurred between the fuel and cladding.

Middle Fuel Pin

The T-lll cladding, separated from the UN fuel by vapor-deposited tungsten, failed after $5800 \mathrm{hr}$ with a cladding-outer-surface temperature of $1400^{\circ} \mathrm{C}$ and a fuel center-line temperature of $1500^{\circ} \mathrm{C}$. Fractures in the cladding were primarily intergranular, with a string of cavities formed at the leading end of the cracks. Electron microprobe examination showed hafnium concentrations at both the cracks and cavities to be as much as 65 wt $\%$ (vs 2 wt $\%$ in base metal). We suspect that nitrogen from the UN fuel may have been associated with the hafnium. A marked increase in the microhardness near the inner surface of the T-lll in the failed region is also indicative of nitrogen pickup from the fuel. Nitrogen content of the irradiated cladding was greater than that of the archive samples. We propose that nitrogen in the cladding during irradiation leads to formation of sufficient helium to cause embrittlement, formation of cavities, and ultimate failure of the T-lll cladding.

Large variations in grain size of the cladding indicate that localized hot spots developed during irradiation. Grain size in the failed region was 6 times that in the gas plenum region, and the failure was located under a thermocouple strap where a gas bubble could form and cause a localized hot spot. We believe this condition determined the 
specific location and time of failure, but the existence of cavities and cracks in other regions of the cladding indicates that failure would have ultimately occurred without the hot spot condition.

Bottom Fuel Pin

This pin was virtually identical to the middle pin both in design and operating conditions. The cavities and cracks in the cladding indicate that additional time or localized temperature excursions would have led to its failure in the same mode as the middle fuel pin.

\section{ACKINOWLEDGMENTS}

The authors gratefully acknowledge the assistance of numerous people without whom the examination of the capsule and evaluation of the findings would not have been possible. In particular, we wish to thank Larry Shrader for performing the metallography on the fuel and cladding, R. L. Lines for disassembly and sectioning of capsule components, S. E. Dismuke for the density determinations of the fuel, and J. L. Miller and T. J. Henson for the microprobe analyses of the cladding and fuelcladding interfaces. The scanning electron microscopy was performed by R. K. Bennett of the Y-12 Development Division and Shirley Mahan of WADCO (now Westinghouse Hanford Company). Chemical analyses were carried out in the laboratory of C. E. Lamb. 


\section{APPENDIX}

Calculation of Helium Production from 100 ppm N in T-1ll

Our method of estimating the helium contents produced from nitrogen impurity in T-11l is similar to that used by Birss 20 in a general review of helium production in reactor materials.

The estimated ORR flux is $5 \times 10^{12}$ neutrons $\mathrm{cm}^{-2} \mathrm{sec}^{-1}(>1 \mathrm{MeV})$. To a first approximation, we assume that the neutron spectrum for energies in excess of $1 \mathrm{MeV}$ is represented by the fission spectrum. Then, the spectrum can be divided into three groups, and, using the effective $(n, \alpha)$ cross sections we can calculate a reaction rate, as shown in Table 6.

Table 6. Rates of ${ }^{14} \mathbb{N}(n, \alpha)$ Reaction

\begin{tabular}{ccccc}
\hline Group & $\begin{array}{c}\text { Minimum Neu- } \\
\text { tron Energy } \\
(\mathrm{MeV})\end{array}$ & $\begin{array}{c}\text { Average Cross } \\
\text { Section, } \sigma \\
\left(\mathrm{cm}^{2}\right)\end{array}$ & $\begin{array}{c}\text { Flux, } \phi \\
(\text { neutrons } \\
\left.\mathrm{cm}^{-2} \mathrm{sec}^{-1}\right)\end{array}$ & $\begin{array}{c}\text { Reaction } \\
\text { Rate, } \phi \\
\left(\mathrm{sec}^{-1}\right)\end{array}$ \\
\hline 1 & $\times 10^{-24}$ & $\times 10^{-12}$ & $\times 10^{-12}$ \\
2 & 3.668 & 0.27 & 0.98 & 0.27 \\
3 & 2.23 & 0.21 & 1.55 & 0.33 \\
& 1.35 & 0.05 & 1.63 & 0.08 \\
& & & Total & 0.68 \\
\hline
\end{tabular}

For an irradiation time of $5800 \mathrm{hr}$, that is $2 \times 10^{7} \mathrm{sec}, 1.4 \times 10^{-5}$ helium atoms are formed per nitrogen atom. Since $100 \mathrm{ppm} \mathrm{N}$ corresponds to $1.3 \times 10^{-3}$ atom fraction and $1 \mathrm{~cm}^{3}$ of $\mathrm{T}-111$ contains about $5.5 \times 10^{22}$ atoms, the number of nitrogen atoms per cubic centimeter in $\mathrm{T}-1 \mathrm{ll}$ is $7.2 \times 10^{19}$. Consequently, about $10^{15}$ helium atoms $/ \mathrm{cm}^{3}$ exist in $\mathrm{T}-111$ at the end of the experiment.

\footnotetext{
${ }^{20}$ I. R. Birss, J. Nucl. Mater. 34, 241 (1970).
} 
INTERINAL DISTRIBUTION

(58 copies)

(3) Central Research Library ORNL - Y-12 Technical Library Document Reference Section

(10) Laboratory Records Department Laboratory Records, ORNL RC ORNL Patent office

G. M. Adams on, Jr.

E. E. BIoom

E. S. Bomar

J. A. Conlin

J. H. Coobs

R. S. Crouse

(3) D. R. Cuneo

F. L. Culler

J. E. Cunningham

J. H. DeVan

R. G. Donnelly

R. B. Fitts

B. Fleischer

J. H Frye, Jr.

R. J. Gray

W. R. Grimes

W. O. Harms

(3) M. R. Hill

F. J. Homan

(3) E. L. Long, Jr.

A. L. Lotts

E. J. Manthos

W. R. Martin

H. C. McCurdy

C. J. McHargue

A. R. Olsen

P. Patriarca

A. C. Schaffhauser

J. L. Scott

J. D. Sease

K. R. Thoms

D. B. Trauger

(3)

J. R. Weir

EXTERINAL DISTRIBUTION

(40 copies)

AEC DIVISION OF REACTOR DEVELOPMENT AND TECHNOLOGY, Washington, DC 20545

J. E. FOX

J. M. Simmons

A. Van Echo

AEC DIVISION OF REACTOR LICENSING, Washington, DC 20545

(3) P. A. Morris

AEC DIVISION OF REACTOR STANDARDS, Washington, DC 20545

(2) E. G. Case

AEC DIVISION OF SPACE NUCLEAR SYSTEMS, Washington, DC 20545

R. E. Anderson

C. E. Johnson 
AEC OAK RIDGE OPERATIONS, P.O. BOx E, Oak Ridge, TN 37830 Research and Technical Support Division

AEC-RDT SITE REPRESENTATIVES, Oak Ridge National Laboratory, P.O. Box X, Oak Ridge, TN 37830

D. F. Cope

C. L. Matthews

ATOMICS INTERNATIONAL, P.O. Box 309, Canoga Park, CA 91304

Sidney Siegel

AAEC RESEARCH ESTABLISHMENT, Materials Division, Private Mail Bag, Suther.land, NSW 2232, Australia.

Adam Jostsons

BATTELIE MEMORIAL INSTITUTE, 505 King Avenue, Columbus, OH 43201

D. Keller

NASA HEADQUARTERS, Code RN, 600 Independence Avenue, Washington, DC 20545

J. J. Lynch

NASA LEWIS RESEARCH CENTER, 21000 Brookpark Road, Cleveland, OH 44135

K. J. Bowles

R. E. Gluyas

A. F. Leitske

N. T. Saunders

TECHNICAL INFORMATION CENTER, Office of Information Services, P.0. BOx 62, Oak Ridge, TN 37830

(2)

(17) Manager (for transmittal to members of ACRS) 